\title{
Advances in FAI Imaging: a Focused Review
}

\author{
Vasco V. Mascarenhas ${ }^{1} \cdot$ António Caetano $^{2} \cdot$ Pedro Dantas $^{3} \cdot$ Paulo Rego $^{4}$
}

Published online: 26 August 2020

(C) Springer Science+Business Media, LLC, part of Springer Nature 2020

\begin{abstract}
Purpose of Review Femoroacetabular impingement (FAI) is one of the main causes of hip pain in young adults and poses clinical challenges which have placed it at the forefront of imaging and orthopedics. Diagnostic hip imaging has dramatically changed in the past years, with the arrival of new imaging techniques and the development of magnetic resonance imaging (MRI). This article reviews the current state-of-the-art clinical routine of individuals with suspected FAI, limitations, and future directions that show promise in the field of musculoskeletal research and are likely to reshape hip imaging in the coming years.

Recent Findings The largely unknown natural disease course, especially in hips with FAI syndrome and those with asymptomatic abnormal morphologies, continues to be a problem as far as diagnosis, treatment, and prognosis are concerned. There has been a paradigm shift in recent years from bone and soft tissue morphological analysis towards the tentative development of quantitative approaches, biochemical cartilage evaluation, dynamic assessment techniques and, finally, integration of artificial intelligence $(\mathrm{AI}) /$ deep learning systems.

Summary Imaging, AI, and hip preserving care will continue to evolve with new problems and greater challenges. The increasing number of analytic parameters describing the hip joint, as well as new sophisticated MRI and imaging analysis, have carried practitioners beyond simplistic classifications. Reliable evidence-based guidelines, beyond differentiation into pure instability or impingement, are paramount to refine the diagnostic algorithm and define treatment indications and prognosis. Nevertheless, the boundaries of morphological, functional, and AI-aided hip assessment are gradually being pushed to new frontiers as the role of musculoskeletal imaging is rapidly evolving.
\end{abstract}

Keywords Femoroacetabular impingement $\cdot$ Hip $\cdot$ Magnetic resonance imaging $\cdot$ Computed tomography $\cdot$ Advanced imaging $\cdot$ Artificial intelligence

\section{Introduction}

Femoroacetabular impingement (FAI) is a motion-driven hip disorder presenting as a specific triad of clinical and imaging findings and is the most common cause of early-onset osteoarthritis (OA) in a non-dysplastic hip $[1 \bullet \bullet, 2 \bullet, 3 \bullet]$. Three distinct types are classically recognized in the literature - the cam, pincer, and mixed types - based on a predominance of either femoral, acetabular, or combined abnormalities. Starting from this over simplistic approach, hip

This article is part of the Topical Collection on Outcomes Research in Orthopedics

\author{
Vasco V. Mascarenhas \\ vmascarenhas@me.com \\ António Caetano \\ aprocaetano@gmail.com \\ Pedro Dantas \\ peddantas@gmail.com \\ Paulo Rego \\ prego@hospitaldaluz.pt
}

1 Musculoskeletal Imaging Unit, Imaging Center, Radiology Department, Hospital da Luz, Grupo Luz Saúde, Avenida Lusíada 100, 1500-650 Lisbon, Portugal

2 Radiology Department, Centro Hospitalar Universitário Lisboa Central, Hospital de Curry Cabral, Rua da Beneficiência, 8, 1050-099 Lisbon, Portugal

3 Orthopaedic and Traumatology Center, Hospital CUF Descobertas, Rua Mario Botas, 1998-018 Lisbon, Portugal

4 Department of Orthopaedic Surgery, Hospital da Luz, Grupo Luz Saúde, Avenida Lusiada 100, 1500-650 Lisbon, Portugal 
analysis became more complex when we included spinopelvic parameters, torsional bone deformities, and malorientation of the femur into the three-dimensional (3D) concept of FAI or hip instability [4]. While this information is helpful, it has mainly been gathered from low-evidence evaluations of procedures that did not help patients in the ways we expected. FAI is responsible for cartilage degradation, labral tears, pain, and development of early OA; and thus, timely diagnosis is essential to provide adequate treatment or preventive measures for such patients [5].

Imaging is established as an important pillar for FAI assessment [6••] as symptoms, clinical signs, and imaging findings must be present to diagnose FAI syndrome (the clinical entity of the biomechanical FAI concept). However, there are still many controversies regarding this entity and a lack of standardized methodology for its definition and imaging evaluation $[7 \bullet \bullet]$.

Imaging assessment of FAI is primarily supported by conventional radiography, the cornerstone technique for the initial evaluation of morphological hip abnormalities [7••].

Computed tomography (CT) and, more specifically, the development of multiplanar reconstructions have allowed for a more accurate depiction of bone morphology in 2-dimensional (2D) and 3D formats, which in turn have served as an important tool for detailed diagnostic structural assessment as well as surgical planning. Magnetic resonance imaging (MRI), on the other hand, has allowed for a more comprehensive analysis of differential diagnosis, osseous structures, and soft tissue components such as articular cartilage and capsule-labral tissue [8]. MR arthrography (MRA) in particular remains the goldstandard technique for patients with suspected FAI due to its accurate depiction of chondro-labral injury and consequently with prognostic capabilities $[6 \bullet \bullet, 7 \bullet \bullet, 8]$. Traction MRA builds on this capability by achieving joint distension and distraction, hence greater lesion conspicuity [9].

Recent major developments of MRI have shifted attention to the unique "all-in-one" imaging capabilities for evaluating bone morphology and soft tissue abnormalities, along with the development of several techniques for detection of early-stage cartilage lesions (quantitative cartilage MRI imaging) [10, 11].

Nevertheless, cross-sectional imaging is still limited in its ability to provide only static morphological information. Research efforts are underway to bridge anatomy and function, by exploring virtual and real-time techniques that may allow for dynamic joint assessment [8]. With increasing interest being drawn towards functional imaging and the advent of deep learning (DL)/artificial intelligence (AI) in the imaging field, exciting new experimental methodologies are currently in development which may shed a new light on the interplay between hip functional dynamics and morphological abnormalities.

Further integrative understanding of the interaction between the joint morphology, function, and load history will possibly lead to an improved screening process to early detect the progression of FAI and provide clinicians with indications of when and where initial chondral-labral damage could occur, when to intervene, and which patients should be safely monitored. Conceptually, early recognition could improve joint preserving surgery outcomes, reduce hip OA cases, and thus, the number of hip arthroplasty surgeries. Several strategies for diagnosis and management of FAI syndrome are currently available and in development.

The near-term future of musculoskeletal imaging may embrace a new paradigm shift to functional assessment and robust early-stage diagnostic tools with well-defined prognostic capabilities (Fig. 1). The long-term perspective includes advanced information synthesis, the combination of multiple findings, patient history, and clinical data in order to reach at a specific diagnosis, individualized prognostic information, and treatment tailoring. Radiologists are in a unique position to welcome the AI revolution in health care as new opportunities to participate in patient care and research are presented.

\section{From Diagnosis to Treatment}

When considering a therapeutic option for FAI syndrome, we must first identify that the pain is truly originating from the hip. Once the hip is confirmed as the culprit, then discussing the pros/cons and risks/benefits with each patient is paramount to critically evaluate which treatment is a viable option (Fig. 2).

Obtaining an accurate diagnosis to direct treatment relies on comprehensive assessment of bony anatomy features (including femoral version), pelvic dynamics and patient characteristics, signs, and symptoms (including sex, age, soft tissue laxity, and range-of-motion). Gathering comprehensive information regarding disease characteristics and patient-specific factors is critical to establish an accurate diagnosis (instability vs impingement).

Imaging Findings are planar 2D static representations of a highly complex dynamic 3D structure. Understanding the required imaging to provide a comprehensive view of femoral cam morphologies can be challenging as the $2 \mathrm{D}$ images obtained with plain radiographs may miss areas of pathomorphology that are not in the plane of the specific radiographic view. The capacity to accurately evaluate the presence of pathology and its precise location may affect many aspects of pre-operative planning, from type of surgical intervention, portal positioning, and even to the selection of anchors for labral repair. Increasing the detail of a surgeon's preoperative knowledge of intra-articular morphology will inevitably enhance treatment safety, accuracy, and effectiveness. 


\section{Natural history and management of femoroacetabular impingement}

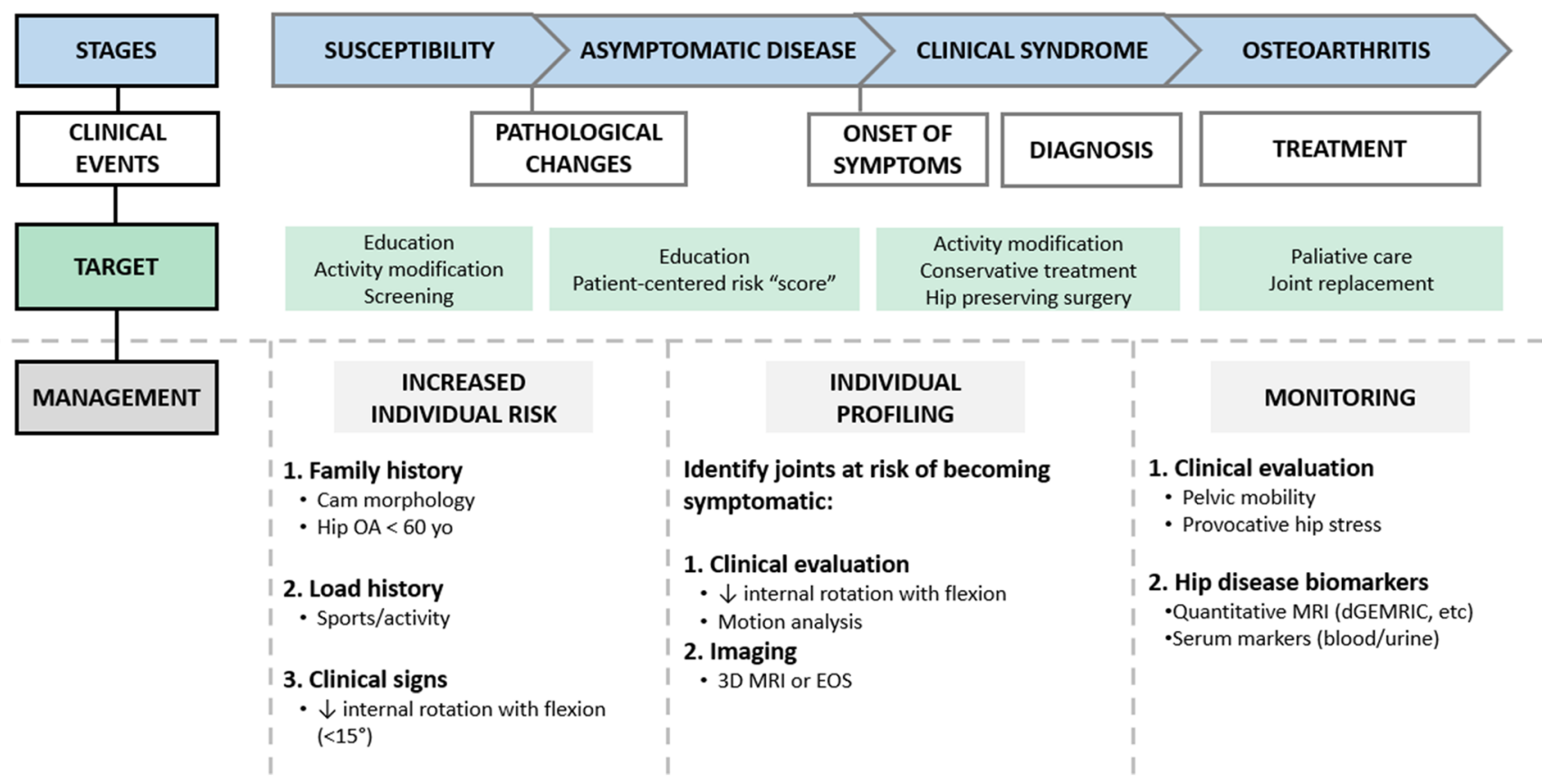

Fig. 1 Natural history of femoroacetabular impingement as known in 2020. dGEMRIC, delayed gadolinium-enhanced MRI of cartilage; MRI, magnetic resonance imaging; OA, osteoarthritis

Treatment Decisions are divided between conservative measures, rehabilitation and hip preserving surgery (HPS).
Periacetabular osteotomy (improving joint stability, optionally combined with arthroscopy) and hip arthroscopy

\section{SUSPECTED FAI}
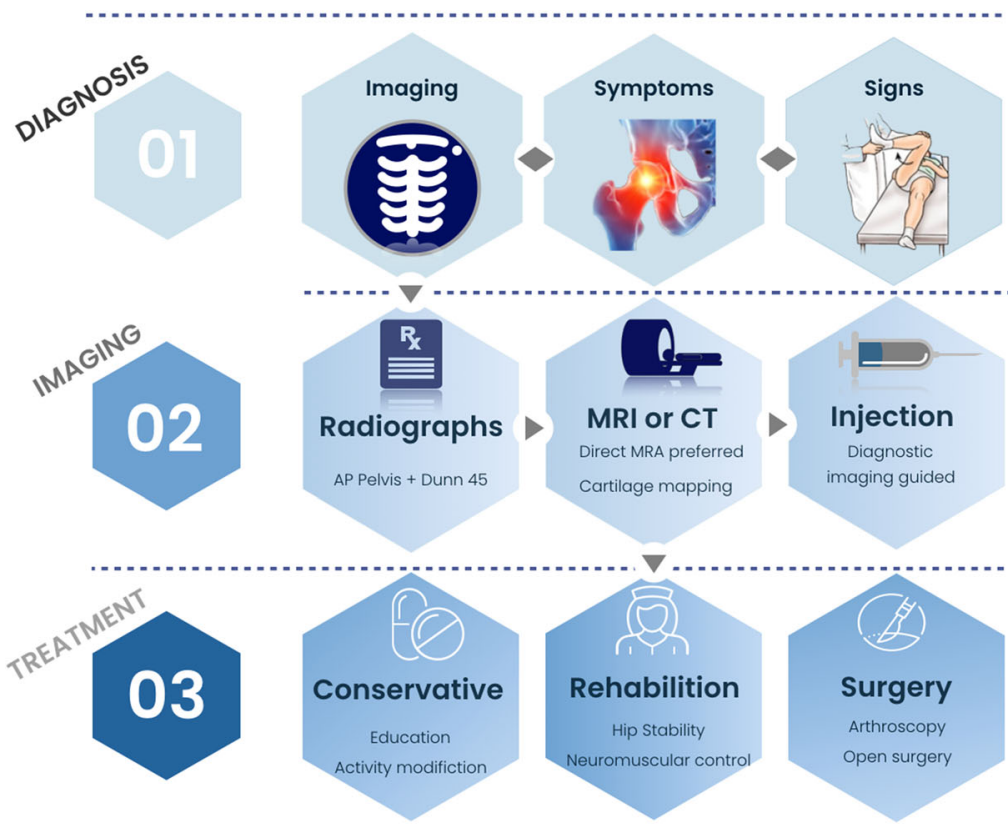

CURRENT STANDARD OF CARE

\section{EMERGING TECHNOLOGIES}

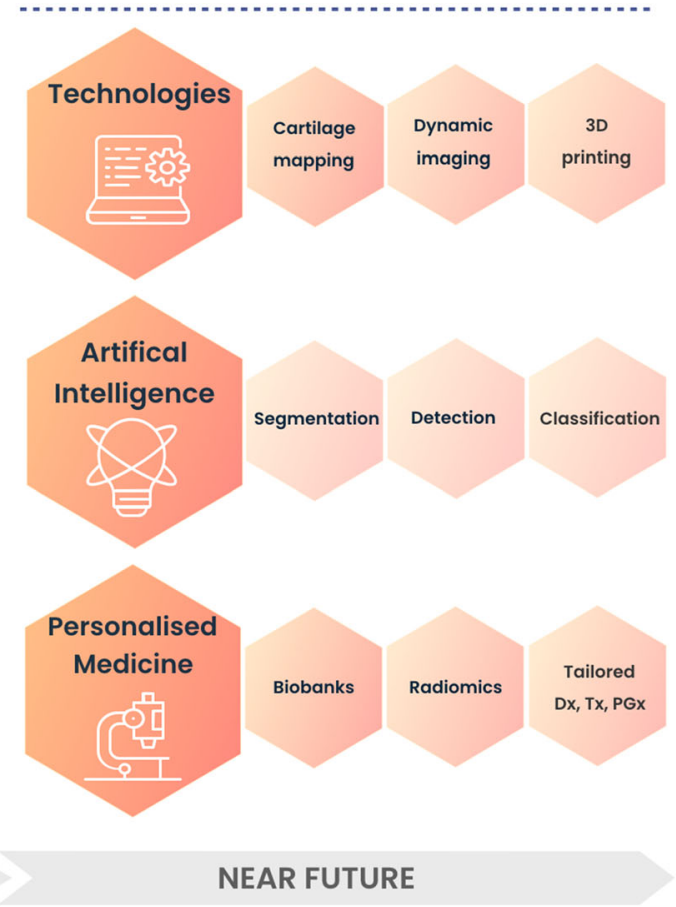

Fig. 2 Overview of current standard of care and future perspectives. MRI, magnetic resonance imaging; CT, computed tomography; MRA, magnetic resonance arthrography; AP, anteroposterior; Dx, diagnosis; Tx, treatment; PGx, prognosis 
(addressing labral tears, chondral damage, capsular laxity, and FAI morphology) remain challenging because frequently the biomechanical fundamental diagnosis (instability vs impingement) can be difficult to determine clinically. The key to successful HPS lies in proper patient selection, surgical expertise, thorough follow-up, and assessing patient-reported outcomes measures (PROMs).

Generally, PROMs lack standardization resulting in difficulty comparing literature results. Accordingly, the gradual use of "Patient-Reported Outcomes Measurement Information System" (PROMIS), "minimal clinically important difference", "patient acceptable symptomatic state," and "substantial clinical benefit" are refocusing hip preservation into a patient-centric value-chain process [12].

\section{Anatomy and Imaging}

\section{Osseous Morphology}

An accurate morphological characterization of hip deformities is quintessential for diagnosis, planning therapeutic intervention, and follow-up. A noted major limitation in the extensive FAI literature has been the wide range of criteria used for FAI, cam, and pincer definitions. Accordingly, specific diagnostic criteria have been proposed by an expert-based panel for classifying cam and pincer morphologies mainly for research purposes [6••] (Table 1). Importantly, further research for its clinical use has to be undertaken as sensitivity, specificity, and intra- and inter-observer consistencies require validation.

Cam Morphology This corresponds to an asphericity of the FHN junction, most commonly at an antero-superior location. The most widely accepted definitions for its diagnosis are either (i) imaging detection of an osseous convexity of the femoral head-neck junction (FHN), (ii) increased alpha angle $\left(\alpha^{\circ}\right)$, or (iii) decreased anterior femoral head-neck offset/offset ratio (Fig. 3). The $\alpha^{\circ}$ and femoral offset (FO) describe different features of the FHN junction. The $\alpha^{\circ}$ reflects the proximal aspect of the asphericity, while the FO describes the width of the femoral neck relative to the femoral head. Although these parameters are useful to quantify the FHN junction particularly in a research setting, caution is warranted when using them in routine clinical practice. The use of the $\alpha^{\circ}$ to quantify cam morphology is controversial due to its moderate reproducibility, moderate discriminative ability to differentiate patients from healthy subjects, and the lack of conclusive data on ideal threshold values $[7 \bullet \bullet, 13,14]$.

Pincer Morphology (Fig. 4) This may be divided in global or focal subtypes. Imaging signs of pincer morphology include markers of increased acetabular coverage and of abnormal acetabular version [15]. Caution is warranted when interpreting radiographs, as pelvic tilt and rotation are known to affect some of these parameters, particularly AP coverage and retroversion. Also, spinopelvic dynamics have a major influence on how specific acetabular morphologies

Table 1 Overview of most relevant femoral and acetabular parameters, notes, and recommendations for research and clinical practice. $A P$ anteroposterior, $F H$ femoral head, $F H N$ femoral-head neck, $W$-CEA Wiberg center-edge angle

\begin{tabular}{|c|c|c|c|}
\hline \multicolumn{2}{|c|}{ CAM MORPHOLOGY (1 or more) } & VALUES & TECHNIQUE \\
\hline \multirow{2}{*}{\multicolumn{2}{|c|}{$\begin{array}{l}\text { A. Osseous convexity of the FHN junction } \\
\text { B. Alpha angle }\end{array}$}} & + & Radiography (preferably AP pelvis and Dunn $45^{\circ}$ ) \\
\hline & & & \\
\hline \multicolumn{2}{|c|}{ C. FHN offset* } & $<8 \mathrm{~mm}$ & Radiography (cross-table view) \\
\hline \multicolumn{2}{|l|}{ D. FHN offset ratio* } & $\leq 0.15$ & CT or MRI (with radial imaging) \\
\hline \multicolumn{2}{|c|}{ PINCER MORPHOLOGY } & VALUES & TECHNIQUE \\
\hline \multirow[t]{2}{*}{$\begin{array}{l}\text { Global Pincer } \\
\text { (1 or more) }\end{array}$} & $\begin{array}{l}\text { Protrusio acetabuli } \\
\text { W-CEA }\end{array}$ & $\begin{array}{l}+ \\
\geq 40^{\circ}\end{array}$ & \multirow[t]{2}{*}{ Radiography (standardized AP pelvis) } \\
\hline & $\begin{array}{l}\text { W-CEA* } \\
\text { Acetabular index* }\end{array}$ & $\begin{array}{l}\geq 35^{\circ} \\
<0^{\circ}\end{array}$ & \\
\hline \multirow{3}{*}{$\begin{array}{l}\text { Global Retroversion } \\
\text { (all criteria) }\end{array}$} & Cross-over sign & + & \multirow[t]{3}{*}{ Radiography (standardized AP pelvis) } \\
\hline & Posterior wall sign & + & \\
\hline & Ischial spine sign & + & \\
\hline \multirow[t]{2}{*}{$\begin{array}{l}\text { Focal Pincer }^{\ddagger} \\
(1 \text { or more })\end{array}$} & Cross-over sign & + & $\begin{array}{l}\text { Radiography (standardized AP pelvis; } \\
\text { confirmation with CT or MRI recommended) }\end{array}$ \\
\hline & Acetabular version & $<0^{\circ}$ & $\begin{array}{l}\mathrm{CT} \text { or MRI (corrected for tilt on coronal plane and } \\
\text { rotation on the axial plane) }\end{array}$ \\
\hline
\end{tabular}

*Both measurements necessary to satisfy this criterion

${ }^{\ddagger}$ Corresponding to cranial retroversion in non-dysplastic hips 


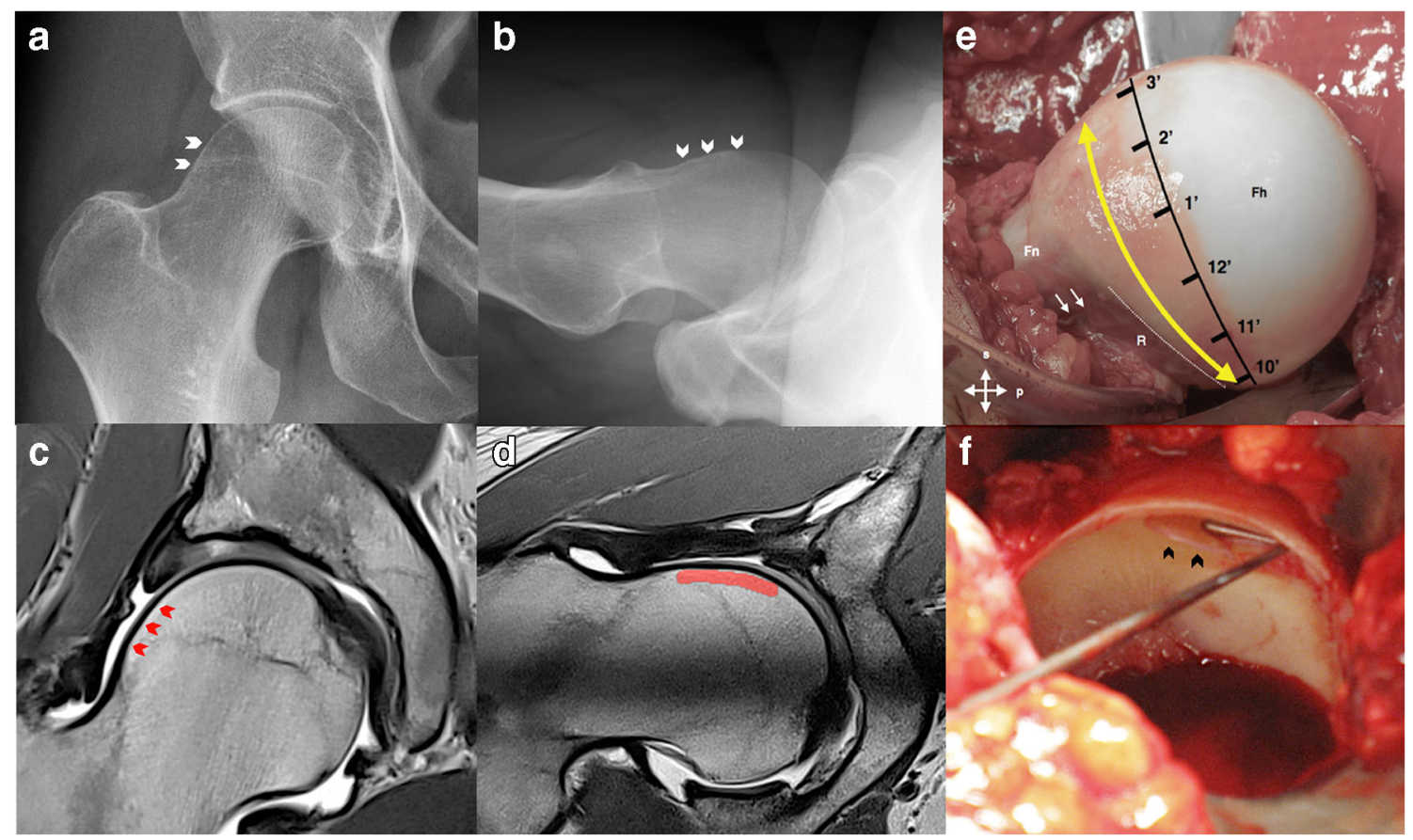

Fig. 3 Cam morphology. Radiographs (a, b), direct arthro-magnetic resonance examination $(\mathbf{c}, \mathbf{d})$, and corresponding surgical hip dislocation procedure $(\mathbf{e}, \mathbf{f})$ in a former athlete. a AP hip-centered radiograph and $\mathbf{b}$ cross-table view show a clear femoral head-neck convexity indicative of a cam morphology (white arrow heads). c Coronal proton density sequence and $\mathbf{d}$ corresponding radial proton density-weighted image at 1:00 o'clock, showing cam morphology (red arrow heads and red curved line), later confirmed by direct observation (curved yellow line in (e)). Also focal cartilage defect, labrum degeneration (c), and chondral delamination (d) are depicted. e Surgical hip dislocation caption showing a cam morphology extending from 10:00 to 3:00 o'clock. f Corresponding acetabular examination confirms extensive acetabular delamination under probing (black arrow heads)

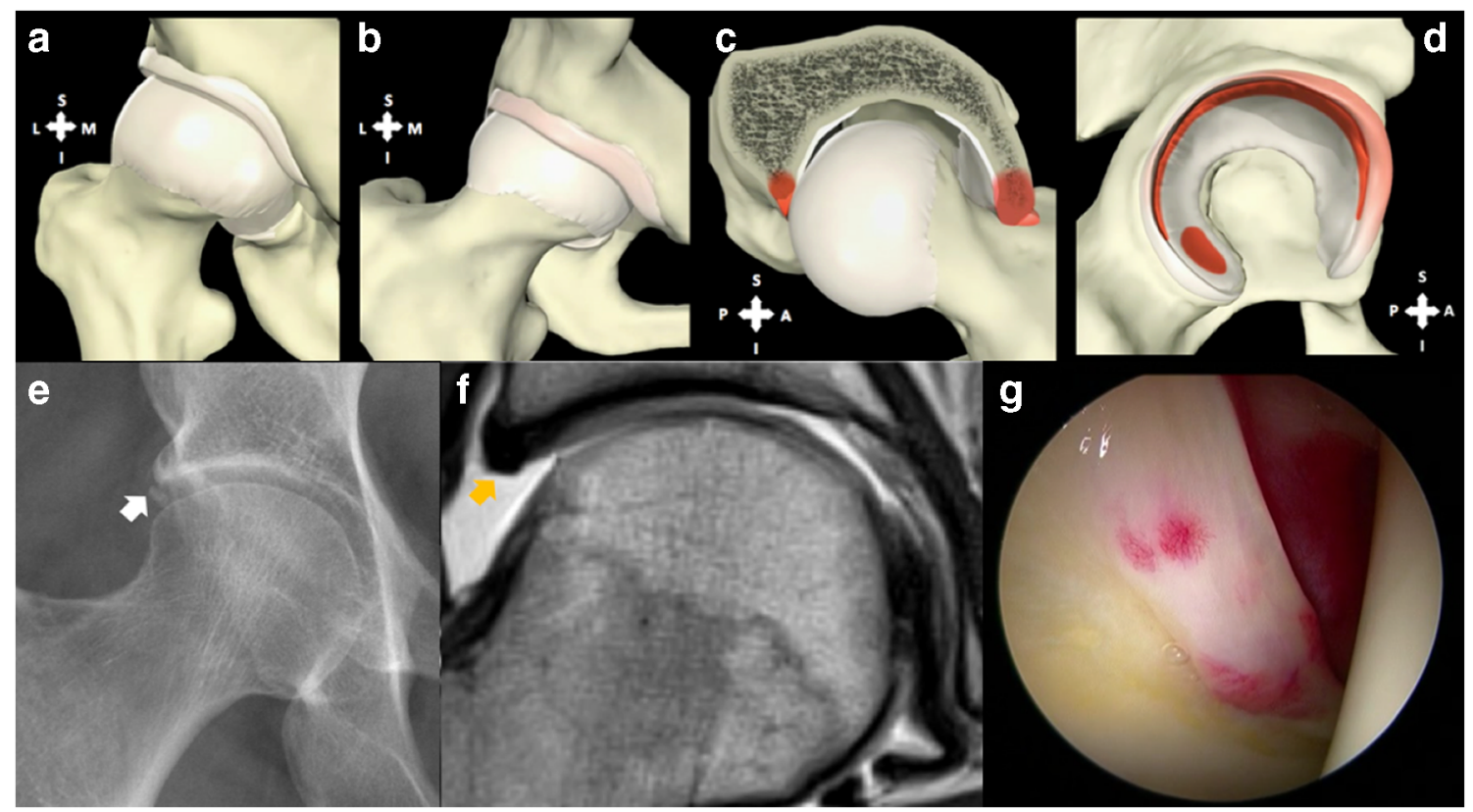

Fig. 4 Schematic representation of the hypothesized mechanism of pincer FAI. a Normal spherical femoral head and acetabulum, which is congruent with the femoral head, provide the hip a wide range-of-motion. A pincer deformity (b) can cause pincer impingement against the femoral neck, especially during terminal flexion of the hip (c) leading to a typical pattern of circumferential acetabular cartilage damage (d). e Acetabular rim ossification and labral ossification associated with acetabular overcoverage, findings usually seen in pincer FAI. (f) MRA of the right hip of a female 26-year-old field hockey player, and arthroscopy (g), same athlete as in (e), revealing (i) a small-sized globular labrum with (ii) peripheral cartilage thinning and (iii) overcoverage of the acetabulum 
might become symptomatic [4]. Although generally supported by the literature, high-quality research is needed in order to more precisely define the value of radiographic signs in the diagnosis of pincer morphologies (particularly the cross-over sign (COS), posterior wall sign (PWS), and ischial spine sign (ISS)), as well as the clinical relevance of cross-sectional imaging in this setting [6••] (Tables 2 and 3 ).

\section{Conventional Radiography}

Pelvic Radiography is still the first preferred imaging method in the diagnosis of FAI syndrome and remains the cornerstone for morphological measurements. Anteroposterior pelvic radiographic and lateral views of the hip are the minimal imaging studies required when evaluating a patient with suspected FAI syndrome [6*0]. Proper radiographic examination and interpretation are the mainstays of the diagnostic process because the symptomatology and physical findings can be nonspecific.

To evaluate for cam morphology, the preferred view is the Dunn $45^{\circ}$ as it allows to best depict the presence of an osseous convexity at the FHN junction and to measure the closest proxy of the highest $\alpha^{\circ}$. The Dunn view in particular increases overall accuracy of detecting FHN junction asphericity as it is often localized on the antero-superior region [16]. The crosstable view is recommended for evaluation of the FO (normal $\geq 8 \mathrm{~mm}$ ) and offset ratio (normal $>0,15$ ) [17].

To evaluate pincer morphology, a standardized AP pelvic radiograph should be the first-line modality of choice. Routine assessment of the Wiberg center-edge angle $\left(20^{\circ}<\mathrm{W}-\mathrm{CEA}<\right.$ $35-40^{\circ}$ ), acetabular index (normal $\geq 0^{\circ}$ ), and presence of protrusio acetabuli should always be reported [15]. Occurrence of global acetabular retroversion can be suspected in the presence of a COS, PWS, and ISS all together. Focal pincer, on the other hand, may be more difficult to determine with radiographs alone, although it can be suspected in the presence of a COS [15]. These findings, however, should be confirmed with CT or MRI reconstructions corrected for pelvic tilt and axial rotation in order to confirm focal pincer morphology $[7 \bullet \bullet]$.

\section{Computed Tomography/Magnetic Resonance Imaging}

Cross-sectional methods and high-resolution MRI have driven a wealth of knowledge in orthopedic and imaging sciences. The widespread application of these novel techniques into clinical practice is the next logical step for enhancing our understanding of intra-articular pathomorphology. Both CT and MRI provide superior capabilities for structural assessment of the hip joint, further improved with the application of volumetric imaging. Morphometric measurements to characterize hip morphology can be much improved using

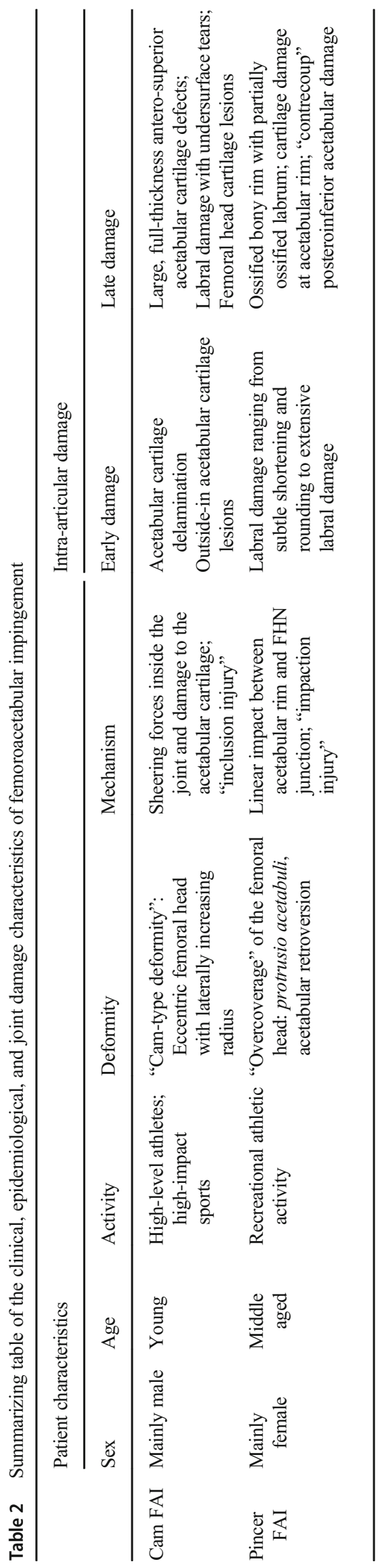


Table 3 Overview of most relevant femoral and acetabular parameters, notes, and recommendations for research and clinical practice. $A P$ anteroposterior, $F H$ femoral head, $F H N$ femoral-head neck, $W$-CEA Wiberg center-edge angle

\begin{tabular}{|c|c|c|c|}
\hline Parameter & Value range & Conventional radiography & Definition \\
\hline Alpha angle & $\begin{array}{l}\geq 60^{\circ} \text { indicates cam morphology } \\
\quad \text { (at any location around the } \\
\quad \text { antero-superior FHN junction) }\end{array}$ & $\begin{array}{l}\text { AP pelvic radiograph } \\
\text { and Dunn } 45^{\circ} \text { view }\end{array}$ & $\begin{array}{l}\text { Angle formed by the FHN axis and line through } \\
\text { the center of the femoral head and the point } \\
\text { where the anterior (posterior) FHN contour } \\
\text { exceeds head radius }\end{array}$ \\
\hline $\begin{array}{l}\text { Osseous convexity } \\
\text { of the FHN junction }\end{array}$ & present or absent & $\begin{array}{l}\text { AP pelvic radiograph and } \\
\text { Dunn } 45^{\circ} \text { view }\end{array}$ & Flattening of the normal concavity of the FHN junction \\
\hline FHN offset & $<8 \mathrm{~mm}$ & Cross-table pelvic radiograph & Difference between the $\mathrm{FH}$ radius and the neck radius \\
\hline FHN offset ratio & $\leq 0.15$ & Cross-table pelvic radiograph & Ratio of offset to the $\mathrm{FH}$ radius. \\
\hline W-CEA & $\begin{array}{l}<20^{\circ}: \text { undercoverage } \\
20-25^{\circ}: \text { borderline } \\
\quad \text { undercoverage } \\
25-39^{\circ}: \text { normal coverage } \\
\geq 40^{\circ}: \text { overcoverage }\end{array}$ & AP pelvic radiograph & $\begin{array}{l}\text { Lateral end of the sourcil, i.e., the weight-bearing } \\
\text { area of the acetabulum, rather than the lateral } \\
\text { rim of the acetabulum }\end{array}$ \\
\hline Acetabular index & $\begin{array}{l}>13^{\circ}: \text { undercoverage } \\
<0^{\circ}: \text { overcoverage }\end{array}$ & AP pelvic radiograph & $\begin{array}{l}\text { Angle formed by a horizontal line and a line through } \\
\text { the medial and lateral edge of the acetabular roof }\end{array}$ \\
\hline Protrusio acetabuli & present or absent & AP pelvic radiograph & Femoral head touches or crosses the ilioischial line \\
\hline Cross-over sign & present or absent & AP pelvic radiograph & Anterior wall crosses the posterior wall \\
\hline Posterior wall sign & present or absent & AP pelvic radiograph & $\begin{array}{l}\text { Positive if the posterior wall runs medially to center } \\
\text { of the femoral head }\end{array}$ \\
\hline Ischial spine sign & present or absent & AP pelvic radiograph & Positive if ischial spine is projected medially to pelvic brim \\
\hline
\end{tabular}

multiplanar reconstructions after cross-sectional acquisitions. In fact, a $3 \mathrm{D}$ perspective of the hip joint allows for a more accurate depiction of morphological abnormalities with less variability $[18,19]$.

The feasibility of 3D CT/MR quantitative measurements has been previously established [18, 19], showing that pincer or cam morphology are frequent in asymptomatic subjects ( $20 \%$ and $71 \%$, respectively) and that there is a positive correlation between W-CEA and acetabular version and age. Furthermore, FHN morphology and, more specifically, cam deformity, can be accurately assessed using novel surface 3D measurements (e.g., the omega angle [19]), obviating the positional, technique, and slice selection disparities associated with $\alpha^{\circ}$ measurements (Fig. 5). Other studies have also validated 3D surface measurements of acetabular coverage profiles using CT and the relationship of cam morphology and
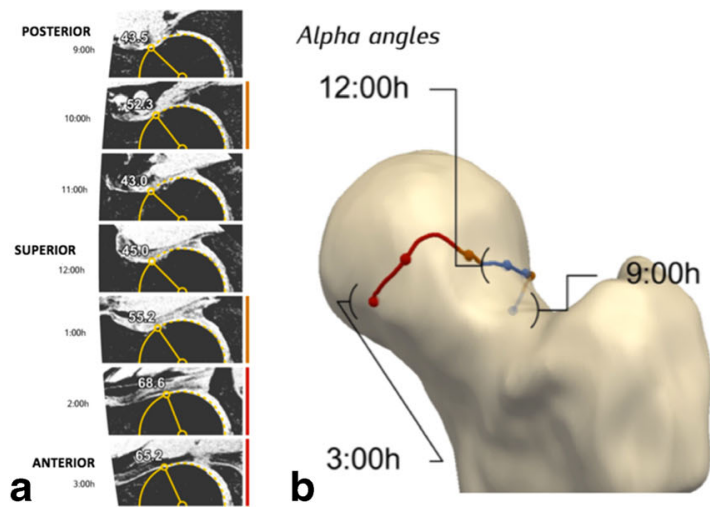

Fig. 5 Automated segmentation and quantification of femoral parameters based on a 3D MRI dataset of a 30-year-old elite soccer player. a Volumetric 3D MRI alpha-angle $\left(\alpha^{\circ}\right)$ automated measurements made at different points around the femoral head/neck junction. $\alpha^{\circ}$ measured at 9 o'clock (posterior); 10,11, and 12 o'clock (superior); and 1, 2, and 3 o'clock (anterior). b 3D generated model representing the radial extension of the cam deformity (orange and red line representing increased alpha angles). c 3D generated model of the corresponding acetabulum with important landmark clock-face references. d Polar plot (2D) of the

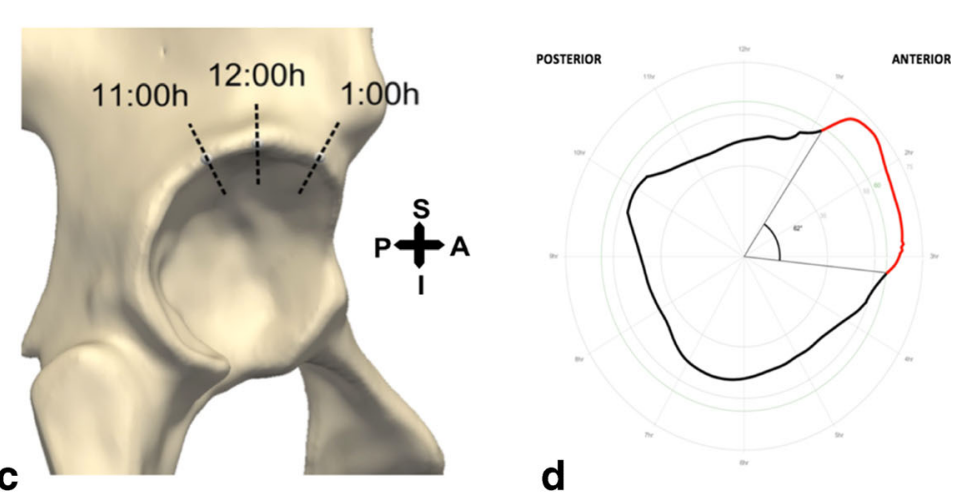

automated $360^{\circ} \alpha^{\circ}$ measurements around the FHN, representing the $\Omega^{\circ}$ angle (gray straight lines) and corresponding perimeter (red line) for a given $\alpha^{\circ}$ threshold $\left(55^{\circ}\right)$. Red lines represent increased $\alpha^{\circ}$ 's for a given threshold. The $\Omega^{\circ}$ is formed by two lines intersecting the center of the femoral neck at the level of the head-neck junction. The most posterior line posteriorly intersects the point at which the $\alpha^{\circ}$ angle begins to be abnormal beyond a best-fitting circle and the anterior line at the point where the $\alpha^{\circ}$ angle returns to normal 
volumetric assessment with anthropomorphic features [20] and intra-operative findings [21].

Furthermore, pelvic 3D MRI evaluation of cam, pincer, and spinopelvic parameters [4] in symptomatic and asymptomatic individuals showed that cam morphology $\left(\geq 60^{\circ}\right)$, acetabular undercoverage, and increased pelvic incidence are predictive of a symptomatic state [4]. The non-inferiority (and in selected cases the superiority) of 3D MRI compared with 3D CT has been studied for patients with FAI with regard to diagnosis [22], pre-operative evaluation [23], cartilage mapping [24], and prognostic capability [25] (Fig. 6).

\section{Labrum, Cartilage, and Capsule}

The degree of chondral damage is the single most important prognostic factor for any HPS [26, 27] (Fig. 7). Importantly, such damage can only be indirectly assessed with conventional radiography through narrowing of the joint space and depiction of secondary OA changes such as osteophytes, subchondral sclerosis, and cysts. Recognition of the importance of labrum and hip joint capsule in hip preservation is presently increasing, particularly for the latter $[28,29]$ as improvements in PROMs have been reported with repair of " $\mathrm{T}$ " capsulotomies and lower rate of conversion to hip replacement after capsular closure. It makes sense to repair wide capsulotomies but it is not clear if the repair of smaller capsulotomies influences PROMs [30]. Regarding the labrum, PROMs have consistently demonstrated significantly better results following labral repair versus debridement. In conjunction with correction of osseous abnormalities, labral surgery can improve short-term outcomes and potentially reduce the risk of long-term osteoarthritis [31].

MRI and Direct MRA These are the techniques of choice to evaluate chondro-labral damage. Several studies have compared direct MRA (dMRA) with MRI and have shown that 1.5 T dMRA performs better than MRI for intra-articular lesions [32-34] and is equivalent to $3 \mathrm{~T}$ MRI for diagnosis of labral tears and cartilage delamination [35]. Furthermore, $3 \mathrm{~T}$ MRI is reportedly superior for diagnosing acetabular cartilage defects when compared with $1.5 \mathrm{~T}$ dMRA and showed similar sensitivity to $3 \mathrm{~T}$ dMRA in the detection of acetabular labral tears [36]. Direct MRA can be combined with leg traction to distract the hip joint and has shown encouraging first results [37] (Fig. 7a, e). CT arthrography may help in the diagnosis of focal cartilage lesions, but lack of soft tissue contrast
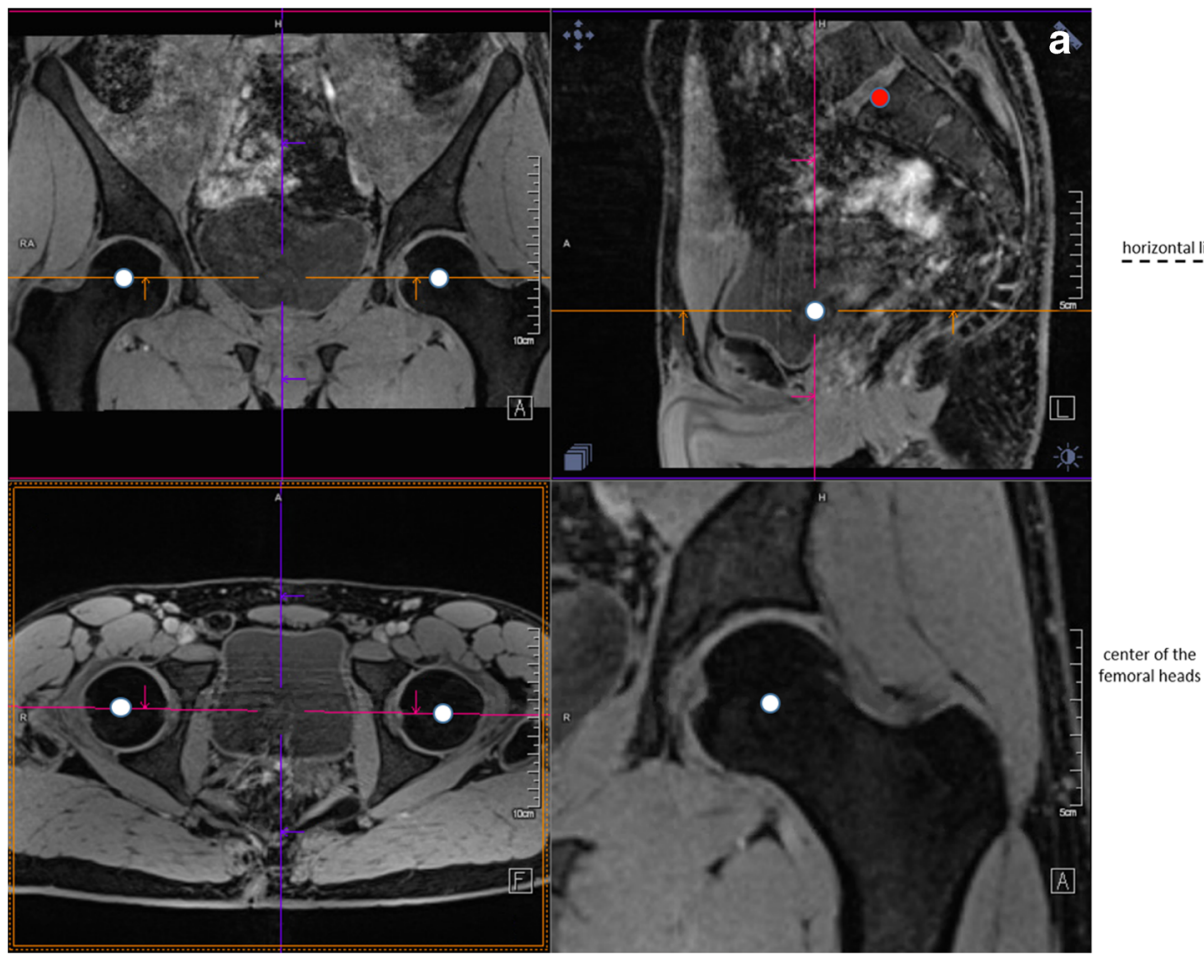

Fig. 6 a MRI volumetric imaging with reformats in all planes allow measurements between examinations and for research purposes, namely to pin-point anatomical landmarks to measure spinopelvic parameters (b). b Spinopelvic parameters schematics. Several steps are methodologically advised such as (1) Correction of tilt on the coronal plane: aligning the superior edges of the femoral heads or the inferior margins of the ischial tuberosities. (2) Correction of rotation in the axial plane: aligning both posterior acetabular wall margins and the antero-superior iliac spines (ASIS). (3) Defining the anterior pelvic plane (APP) (correction for tilt in the sagittal plane): aligning the ASIS and the anterior edge of the pubic symphysis. The APP is thus defined by three bony landmarks, the ASIS on both sides, and the pubic symphysis. The angle between the APP and the horizontal is defined as the APP angle 

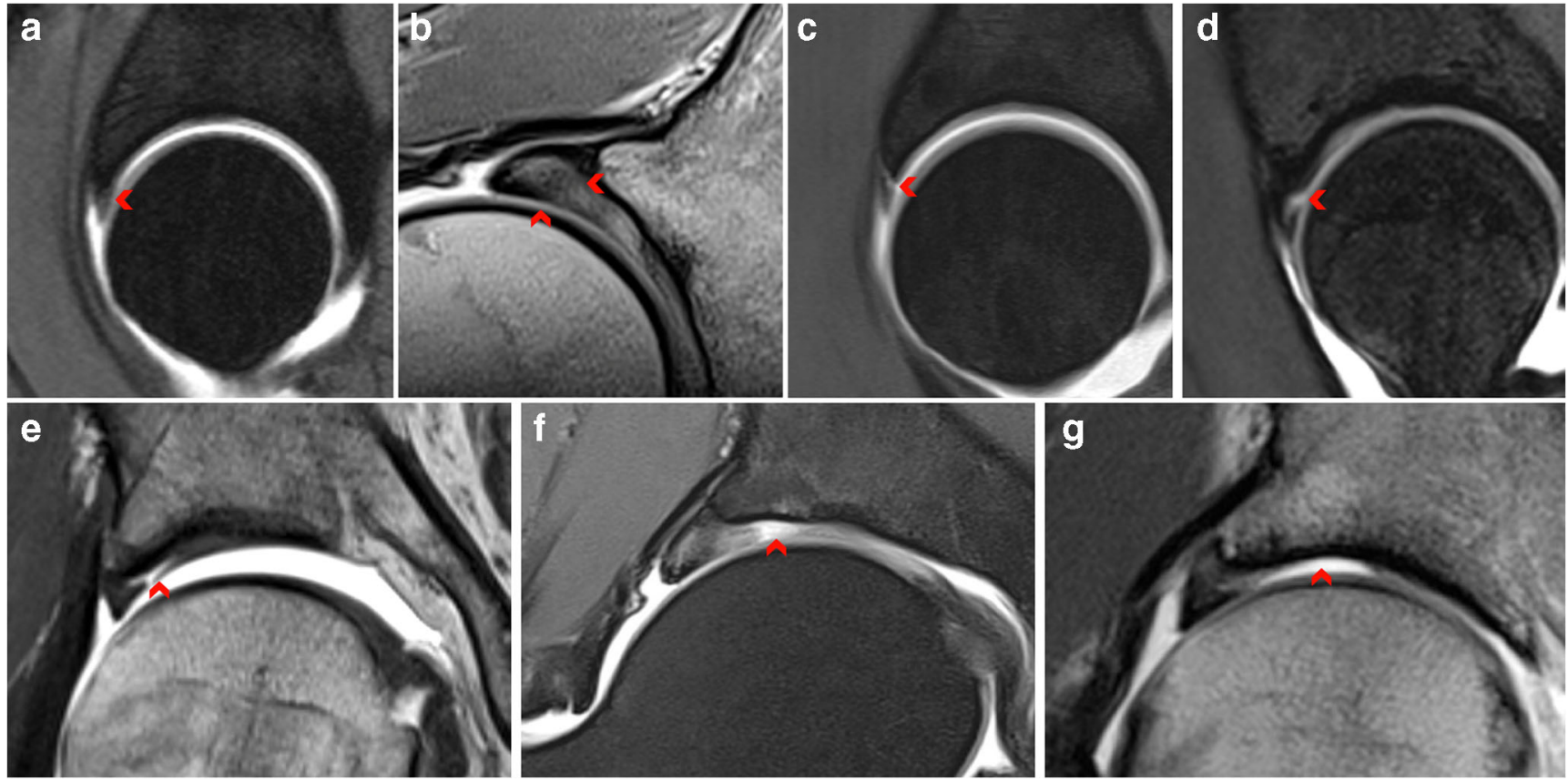

Fig. 7 Labrum tear patterns (a-d) and cartilage lesion patterns (e-g). a Intrasubstance labrum degeneration; sagittal plane. b Intrasubstance labrum degeneration and hypertrophy; radial plane at 1.5 o'clock. c Labral-chondral separation (= labral detachment); sagittal plane. d Intrasubstance labrum tear; sagittal plane. e Grade 2: partial thickness

cartilage damage (peripheral acetabular chondral delamination involving the chondro-labral junction; outside-in pattern). f Complete cartilage loss (focal full-thickness acetabular cartilage defect). $\mathbf{g}$ Complete cartilage loss (diffuse full-thickness acetabular cartilage loss)

resolution renders the technique less useful when MRI is readily available.

Accordingly, the evaluation of a suspected patient with FAI syndrome may now follow an algorithmic pathway in order to comprehensively assess osseous morphology, labrum, and cartilage damage as well to address differential diagnosis (Fig. 8).

\section{Advanced Imaging-From Qualitative to Quantitative Imaging}

Advances in 3D MRI techniques have created the opportunity to improve our understanding of articular morphology and joint biomechanics.

Fig. 8 Pathway for the imaging management and assessment of femoroacetabular impingement syndrome (FAIS). W, with; Wo, without; AP, anteroposterior

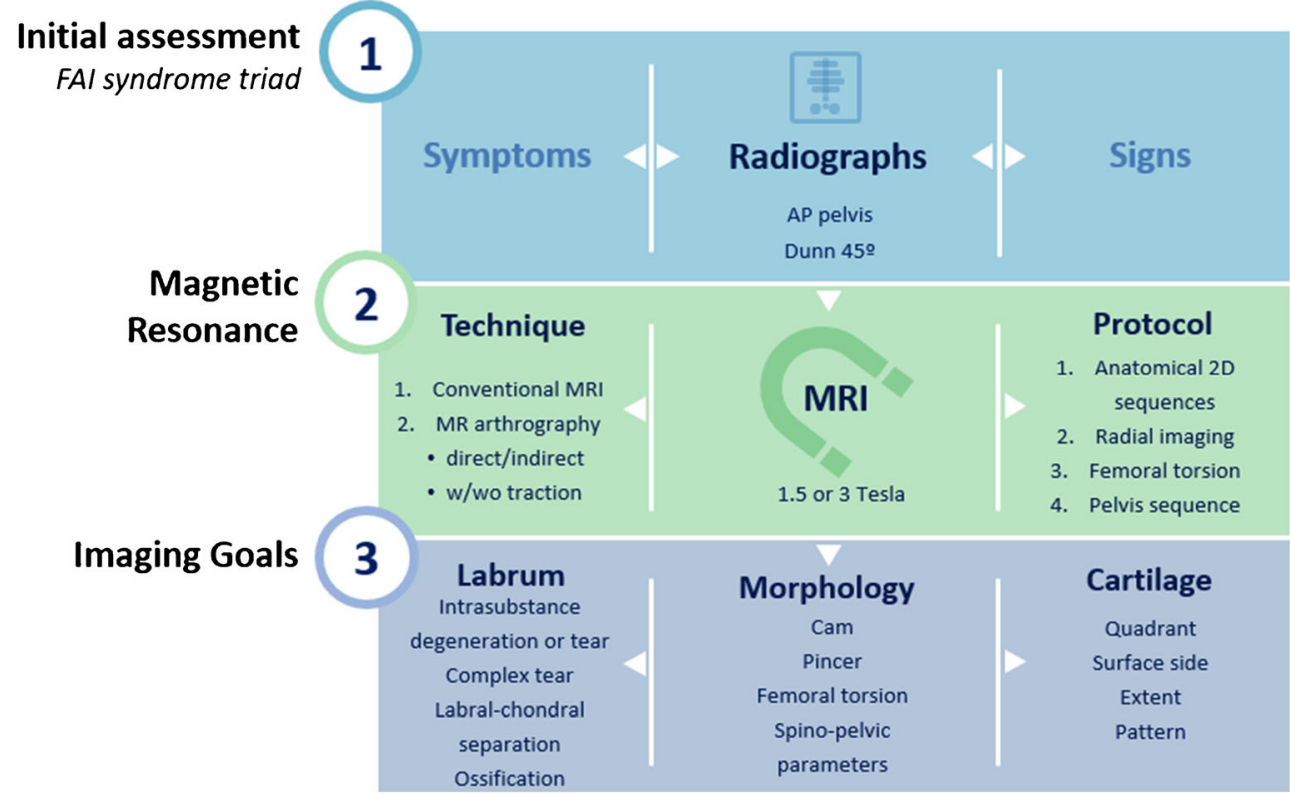




\section{Automated Image Analysis}

Automated bone segmentation methods have been performed using conventional radiography [38], CT [39, 40], and MRI [41]. Machine learning-based methods have been tried out for knee cartilage segmentation [42] and 3D volume-to-volume segmentation using convolutional neural networks $(\mathrm{CNN})$. Zeng et al. proposed a framework for 3D segmentation of the proximal femur using MRI which was validated for FAI patients [41]. Such techniques will allow for automatic methods of determining contours and volumes in zones of interest in a timely manner to be used in fast post processing of medical images. This allows radiation-free and patient-specific pre-operative 3D modeling for surgical planning. Using a healthy and cam-type morphology hip joint model developed with finite element analysis, it was possible to demonstrate that the latter elevates stress in the cartilaginous tissue and contributes to joint wear [43].

\section{Quantitative Osseous Assessment}

\section{Bone Modeling}

3D hip modeling has been made possible thanks to reconstruction algorithms from 2D/3D CT [18] acquisitions and, more recently, 3D MRI data sets [4, 24]. Such studies may aid the surgeon in pre-operative planning, intra-operative guidance, and post-operative follow-up of FAI patients, who frequently show abnormal complex 3D bone and soft tissue abnormalities. 3D data sets have been used to simulate individual bone morphology, evaluate range-of-motion (ROM), and perform virtual analysis [44].

CT/MR images can be used to create shape models, compare, and quantify differences in bone or cortical thickness between patients with cam deformity and controls [45]. Anatomical differences and identification of ideal shape can be assessed using correspondence-based computing methods such as statistical shape modeling $[14,18]$.

\section{Synthetic CT and Zero Echo Time MRI}

A simple method of displaying cortical bone in MRI with tissue contrast resembling CT by taking advantage of the very short relaxation time of bone is by using zero echo time imaging [46]. This technique has the advantage of having no radiation and allowing for near-isotropic resolutions necessary for morphological measurements.

A different technique named synthetic $C T$ refers to a technology allowing the generation of a CT surrogate from an MRI-derived input. Recently, deep learning-based models used several MR input configurations to generate such models [47] (Fig. 9).

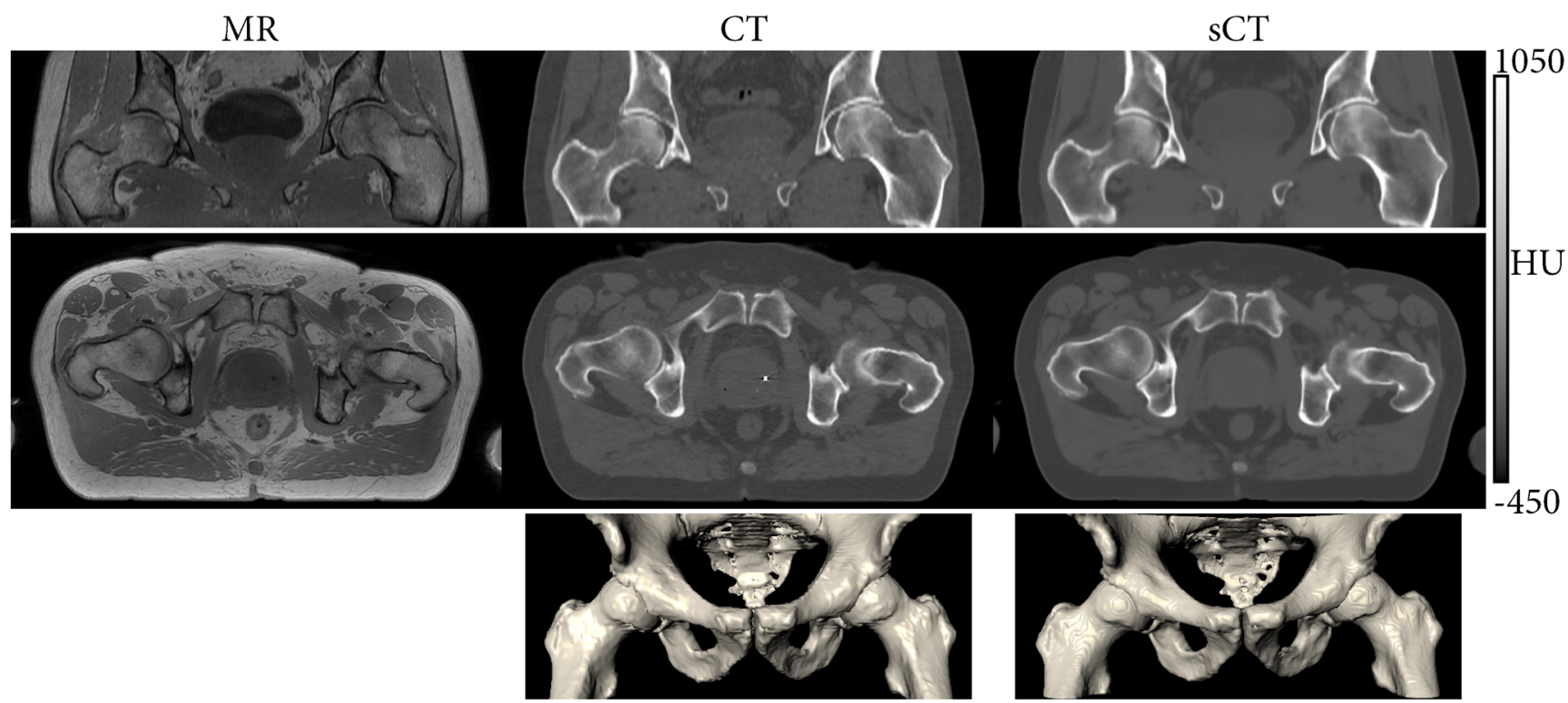

Fig. 9 Synthetic CT derived from MRI-based information. T1-weighted MRI (left column), CT (middle column), and synthetic CT (right column) images of the pelvic area. The SCT images, reconstructed from the T1wMRI images using a pre-trained deep learning algorithm strongly, resemble the CT images, the current standard for $3 \mathrm{D}$ imaging of osseous morphology. The 3D nature of the synthetic $\mathrm{CT}$ reconstruction facilitates multiplanar reconstructions, as demonstrated by the coronal (upper row) and axial (middle row) images as well as 3D renderings (lower row). (Courtesy of P.R. Seevinck, University Medical Center Utrecht, The Netherlands; boneMRI v1.1, MRIguidance BV, Utrecht, The Netherlands) 


\section{Quantitative Cartilage Mapping}

MRI techniques have been developed to characterize and quantify biochemical properties of cartilage, which include traditional relaxometry sequences (T2/T2*, T1rho and T1), sodium imaging, delayed gadolinium-enhanced MRI of cartilage (dGEMRIC), glycosaminoglycan specific exchange saturation transfer, diffusion weighted imaging, and diffusion tensor imaging $[8,10]$. Such techniques are feasible, although with variable reproducibility, and have the potential to provide objective markers with clinical and research utility (Fig. 10). Main advantages include (i) early cartilage damage diagnosis (thus enabling timely treatment before joint damage is established), (ii) visual representation for surgical planning, and (iii) use as a precise biomarker for monitoring and follow-up (Table 4).

Recently, it was shown that quantitative MRA is feasible and reliable for usage in FAI patients [48]. This technique not only allows for evaluation of cartilage damage, but also detailed assessment of labral pathology through the use of intraarticular contrast.

Although compositional cartilage techniques were validated histologically yielding promise as prognostic or longitudinal biomarkers which can be implemented into a clinical routine protocol, the time-consuming and reader-dependent analysis has limited their clinical routine use. A full-automatic DL approach for segmentation/ quantification of 3D cartilage models [49] was recently presented that may pave the way for widespread use of a volumetric analysis of cartilage geometry and cartilage composition.

\section{Advanced Imaging-Analyzing Function}

\section{Virtual Function}

\section{Imaging-Based Dynamic Range-of-Motion Simulations and Virtual Surgery}

Dynamic assessment of FAI with simulated ROM tests, collision detection and accurate visualization of morphologic changes have shown utility for pre-operative planning [50]. Dedicated software tools have been developed to post-process CT and MRI acquisitions and assess hip ROM with simulated osseous trimming [50].

Recent evidence performed simulated 3D ROM studies in patients with FAI using CT-based models although MRI is established as an ideal substitute also for this purpose [24, 51]. In fact, MRI-based 3D models are expected to be adopted in future clinical practice as these allow radiation-free and patient-specific pre-operative 3D impingement simulation for surgical planning and simulation of HPS (Fig. 11). Examples of software currently available include the following: HipMotion [52] and Dionics PLAN Hip Impingement Planning System (Smith \& Nephew, Andover, MA).

\section{Computer-Based Navigation}

$3 \mathrm{D}$ imaging and computer navigation may play a role in planning hip surgery and preventing complications (such as under or over resection). In fact, such a technique has been implemented in FAI surgery and may be used to synchronize 3D CT data sets with intra-operative fluoroscopy [44]. Van Houcke et al. compared bone resection accuracy in revision surgery for
Fig. 10 MRI cartilage quantitative imaging. Preoperative imaging of a 25 -yearold male with cam-type FAI. a radial $\mathrm{T} 2 *$ mapping color-coded measurements at $3.0 \mathrm{~T}$ show decreased $\mathrm{T} 2 *$ relaxation times in the central compartment (anterosuperior quadrant). b Proton density fat-saturated corresponding radial morphological sequence. c Corresponding MRI-derived 3D model with superimposed cartilage quantitative mapping
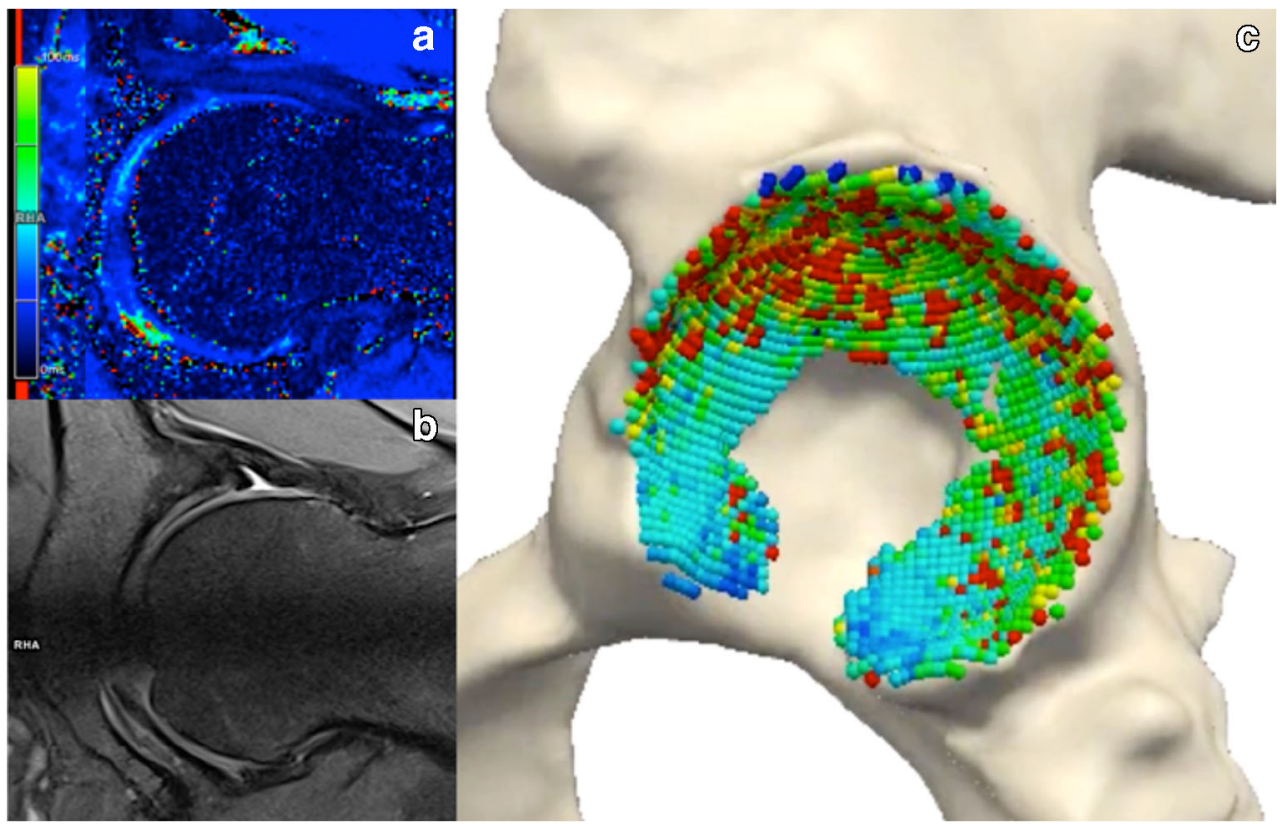


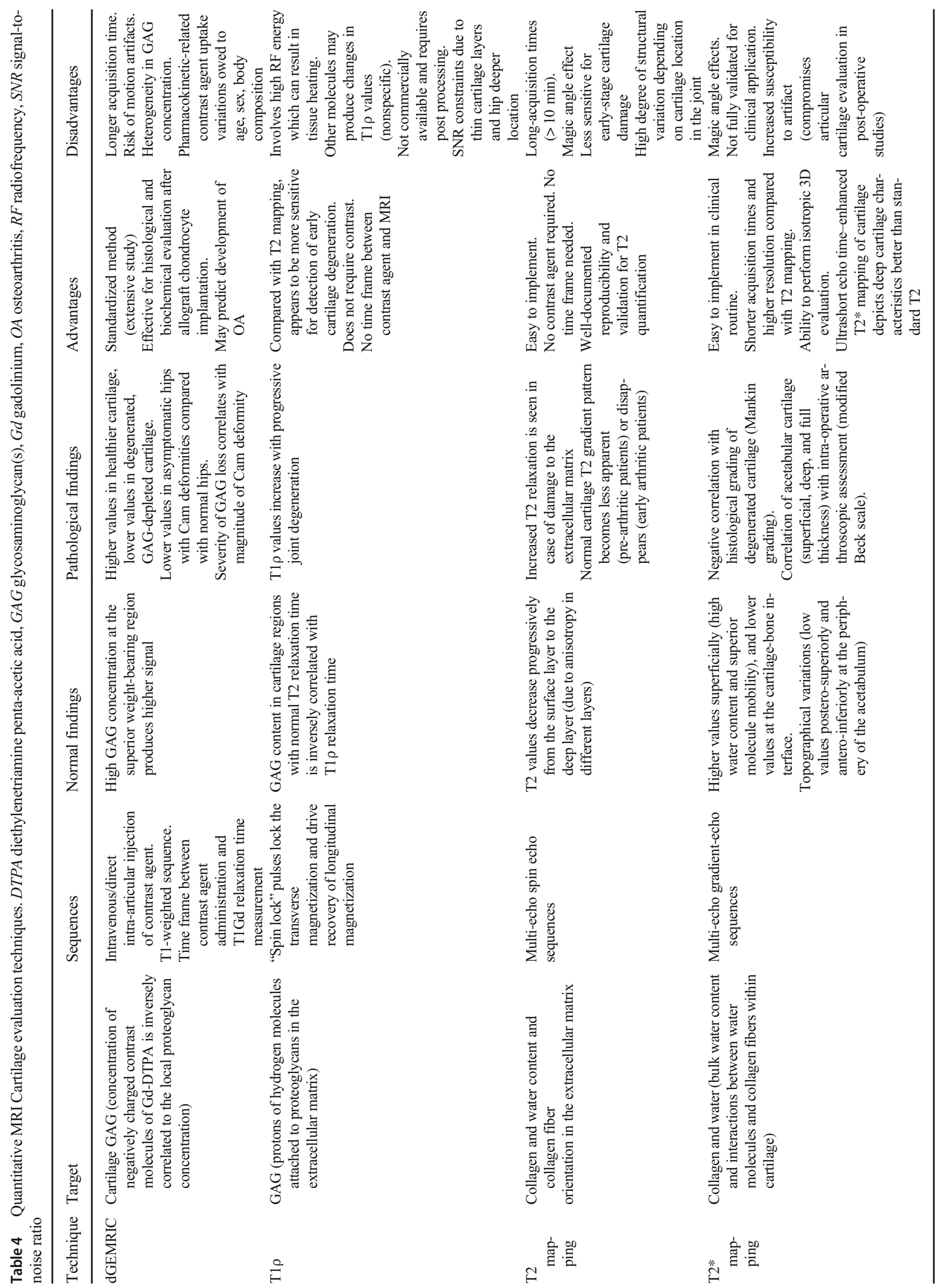



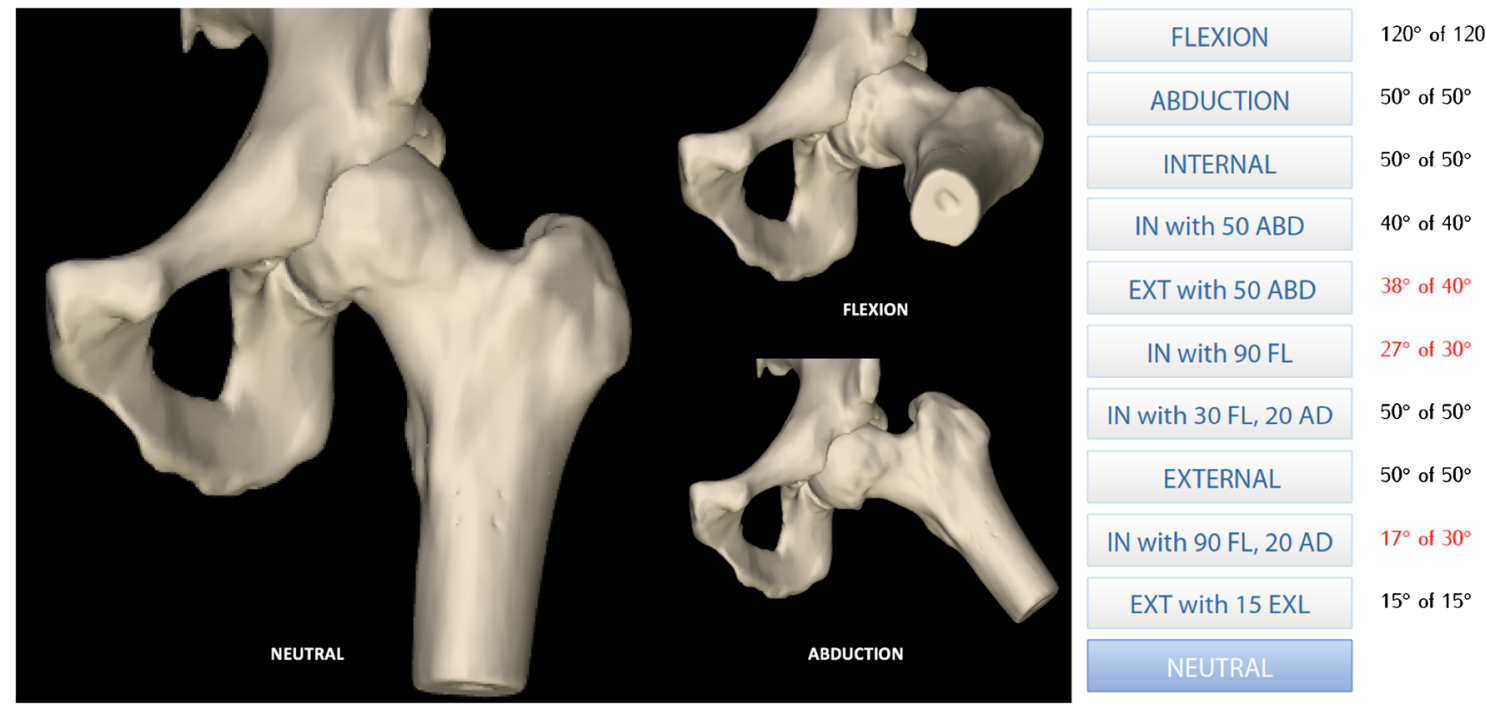

Fig. 11 MRI-based 3D modeling and dynamic virtual assessment. Virtual ROM detects impingement areas at specific degrees of motion represented on the right. In this 35-year-old male with a cam deformity, there was impingement noted at $17^{\circ}$ of internal rotation with $90^{\circ}$ of flexion and $20^{\circ}$ adduction

FAI patients through navigated surgery versus conventional surgery and showed improvement in mean maximal alpha angle and simulated increased bony ROM, however, with increased radiation exposure and longer installation time [53]. Again, MRI can adequately overcome these limitations.

\section{Real-time Function}

As FAI is a motion-driven disorder, a detailed understanding of the underlying biomechanical mechanisms would be ideal to better appreciate why specific hip morphologies become symptomatic. True real-time imaging has previously been limited by factors such as (i) the required high temporal resolution, (ii) the need for mechanisms to control motion speed, and (iii) the requirement for post- processing, which have made performing these scans impractical in routine clinical settings. Presently, real-time in vivo ROM testing can be performed using MRI acquisition. MRI has some advantages compared with computer simulations, ex vivo studies, and virtual simulations for assessment of FAI, namely to detect intra-articular intrusion of the cam deformity and changes in femoroacetabular contact forces [54].

High accuracy to pre-operatively detect FAI using 4D volume CT was reported, as a functional investigation to diagnose FAI may be associated with greater diagnostic accuracy. In fact, it can offer direct visualization of osseous pathologies and the resulting premature femoroacetabular contact [55]. Fernquest et al. studied 50 patients who underwent 4D dynamic CT scanning of the hip and performed different types of motions and the results showed that cam-type FAI may occur early in flexion and these patients might be at risk while performing routine activities such as walking or climbing stairs [56]. Burke et al. attempted analysis of dynamic femoroacetabular motion in routine clinical practice using radial GRE sequences and MRA assessment in healthy and FAI patients, showing a strong interreader agreement and correlation of femoroacetabular cortical space narrowing between FADIR (flexion, abduction, internal rotation) test and neutral position [57].

The role of dynamic MRI techniques for the diagnosis of complex cases is currently uncertain as this technique is at an early stage of development. Optimistically, dynamic MRI can presently be only used in the research setting to answer clinically important questions such as understanding pain mechanism and functional biomechanics.

\section{Future Trends}

\section{D Printing}

Data generated from volumetric data sets can be adopted by 3D printing technology and enable production of patientspecific models that improve understanding of FAI as well as pre-operative counseling. Furthermore, virtual surgical planning may guide osteochondroplasty and prove useful to achieve optimal results. In a retrospective study carried out by Wong et al., 3D printed models of patients' affected hip changed the planned osteoplasty, especially in patients with high alpha-angle measurements and without radiographic COS [58].

$3 \mathrm{D}$ printing might represent a step forward towards patientoriented tailored management, taking into account individual anatomical characteristics and predicting the best hardware and surgical approach to achieve the best outcomes [59]. 


\section{Magnetic Resonance Fingerprinting}

Magnetic resonance fingerprinting introduces a new approach to probing distinct properties from tissue than those originally studied by conventional MR experiments [60]. Non-invasive quantification of multiple properties of material or tissue can be acquired with different methods of data acquisition, postprocessing, and visualization. This technique could identify the presence of targeted molecules or tissue-specific material and analyze simple/complex changes that could represent disease surrogates.

\section{Personalized Medicine and Imaging Biobanks}

Imaging biobanks are defined as "shared organized databases of medical images and associated imaging biomarkers, linked to other biorepositories." Such biobanks may serve as tools for research validation or generation and discovery of novel imaging biomarkers [61]. Furthermore, they could be integrated with other existing biobanks and provide a robust network for future research studies. Understanding the pros and cons associated with large databases is fundamental. The implementation of conjoined orthopedic and imaging registries might ultimately lead to improvement of patient care and minimize the economic burden $[62,63]$.

To date, there are dozens of imaging biobanks which are mostly disease oriented, although access is frequently restricted. There has been some research regarding clinical and genetic factors associated with OA [64] and inflammatory biochemical markers associated with mortality in hip fracture patients (participants from the UK Biobank study). To the best of our knowledge, there is currently no published study regarding FAI using imaging biobanks shared among multiple research groups. Such tool, however, could prove invaluable for FAI biomarker identification through large-scale data analysis with the opportunity of clinical and genetic cross reference [65].

\section{Artificial Intelligence}

Artificial Intelligence (AI) will certainly pave the way for better and comprehensive MSK pathology assessment. In the medical context, AI refers to devices or systems that can perceive some element of their environment and use this information to achieve a predefined goal. It has been regarded as the next big wave in the computing revolution and transformative technology for radiology, healthcare, and humanity [66]. To be adopted in clinical practice, AI applications must address unmet needs or improve on existing solutions. Overall, applications of AI in radiology generally fall into one of the following categories: (i) detection, i.e., to identify an anomaly in an image (e.g., cam morphology); (ii) segmentation, i.e., a structure of interest is isolated from the remainder of the study (e.g., isolating the femoral head and acetabulum); (iii) classification, i.e., a morphology is assigned to a category (e.g., acetabular overcoverage present or not) [67] (Fig. 1). Additionally, DL and CNN (which represent specific forms of AI) can further enhance complex clinical analysis that will probably reshape healthcare.

Computer-Aided Diagnosis Computer-aided diagnosis methods, which represent the basic capability of AI, are designed to help physicians detect imaging abnormalities with increasing accuracy. AI might also have a large impact on the importance of imaging biobanks in the near future, as large amounts of data are necessary to train AI neural networks in order to have satisfactory performance in a clinical setting [65].

Using a binary classifier (normal vs abnormal), some authors reported that a CNN was able to automatically detect hip osteoarthritis on radiographs with performance comparable with that of an attending radiologist with 10 years of experience (sensitivity of $95 \%$, specificity of $90.7 \%$, and accuracy of 92.8\%) [68]. Recently, a multitask DL model reliably assessed five radiographic hip osteoarthritis features per joint on radiographs (femoral osteophytes [FOs], acetabular osteophytes [AOs], joint space narrowing [JSN], subchondral sclerosis, and subchondral cyst). The accuracy of the model for assessing these five features varied depending on the evaluated feature: $89 \%$ for FOs, $76 \%$ for AOs, $83 \%$ for JSN, $96 \%$ for subchondral sclerosis, and $97 \%$ for subchondral cyst [69].

Other studies on DL and hip imaging have involved estimation of pelvic sagittal inclination in AP radiographs, segmentation of the proximal femur in radial MRI scans, osteonecrosis of the femoral head on digital radiography, proximal femur segmentation from MR images, and hip osteoarthritis on plain radiographs (Table 5).

Future research may explore DL and CNN capabilities focusing on (i) fully automated hip bone, cartilage, capsule, and labrum segmentation (ii) enabling large-scale radiomic analysis with the potential to (iii) identify disease characteristics based on imaging patterns that may not be readily apparent to the human eye. "Big data" techniques, consisting of both DL and other machine learning strategies, may also allow for better identification of at-risk subgroups and prediction of response to therapy, by providing information on which patients may benefit from conservative care as opposed to surgery. Ideally, future AI-based models where an individual patient data can be entered and each patient's individual risk and outcomes can be estimated are the holy grail of HPS. This would allow the patient and the surgeon to make a more educated decision.

\section{Research Pipeline}

Literature regarding FAI may be broadly divided in main research areas, such as (i) etiology, (ii) diagnosis, (iii) natural history and prognosis, and (iv) treatment (Table 6). 
Table 5 Summary of AI-related studies focusing on hip imaging with clinical applications. $2 D$ 2-dimensional, $3 D$ 3-dimensional, $A V N$ avascular necrosis, $C N N$ convoluted neural networks, $C T$ computed tomography, $M R$ magnetic resonance, $F A I$ femoroacetabular impingement, $O A$ osteoarthritis, $Q C T$ quantitative CT, $S s$ sensitivity, $S p$ specificity, THA total hip arthroplasty

\begin{tabular}{llll}
\hline Study & Year & Technique & Clinical application \\
\hline Ureten et al. & 2020 & Pelvic radiograph & Radiological screening of hip osteoarthritis \\
$\begin{array}{c}\text { Schacky } \\
\text { et al. }\end{array}$ & 2020 Pelvic radiograph & $\begin{array}{l}\text { Assessment of hip osteoarthritis features } \\
\text { (femoral osteophytes, acetabular } \\
\text { osteophytes, joint space narrowing, } \\
\text { subchondral cysts) }\end{array}$
\end{tabular}

Yu et al. 2019 Hip radiograph Detection and localization of hip fractures

Chee et al. 2019 Digital radiography Detection of femoral head osteonecrosis of the hip

Chandran 2019 CT
et al.

Badgeley et al.

2019 Hip radiograph, patient data and hospital process variables

Jodeiri et al. 2019 Pelvic radiograph (anterior-posterior)

Damopoulos 2019 Radial 2D MR scan et al.

Adams et al. 2018 Anteroposterior hip radiograph

Zeng et al. 2018 T1-weighted MR images

Xue et al. 2017 Pelvic radiographs
Estimation of pelvic sagittal inclination to assessmalposition of the acetabular component of THA

Bone shape and cortical thickness estimation (fracture risk assessment)

Combine image features with patient data and hospital variables extracted from image pixels to better predict hip fracture

Segmentation of the proximal femur (surgery planning for correction of Cam FAI or AVN)

Detect femoral neck fractures

Segmentation of the proximal femur

Binary hip osteoarthritis classification (normal or OA)
Conclusions

Accuracy, specificity and precision for hip osteoarthritis diagnosis shows promising results

Varying grading reliabilities depending on the evaluated feature, but overall similar to that of attending-level radiologists: lower for subchondral sclerosis and acetabular osteophytes, higher for joint space narrowing, and femoral osteophytes

High accuracy for detection of acute proximal femoral fractures (Ss and $\mathrm{Sp}$ of $97.1 \%$ and $96.7 \%$ ); lower Ss for characterizing location $(84.1 \%$ for sub capital/transcervical, $77 \%$ for basicervical/intertrochanteric, $20 \%$ for subtrochanteric)

Overall performance was lower than that of radiologists, especially in localizing fracture location

Hip fracture detection with low false-negative rate and high accuracy for localization of lesions

Sensitivity to detect osteonecrosis of the femoral head was noninferior to that of radiologist assessment and was superior to less experienced radiologist assessment in diagnosing pre-collapse

Automatic generation of bone meshes from QCT scans for finite element analyses with equal performance for cortical thickness estimation compared with previous works

Radiograph pixels can be used to predict disease, patient, and hospital process variables.

Combination of covariates boosts predictive performance (pre-test probability of disease) through statistical learning algorithms

Robust and fully automatic framework for estimation of the pelvis sagittal inclination using anterior-posterior pelvic radiograph

Validation of a semi automated method for segmentation of the proximal femur from radial 2D MR scans of the hip

$3 \mathrm{D}$ reconstruction model useful for hip-preserving surgery planning

Perceptual training carried out by top-performing medically naive humans for $1 \mathrm{~h}$ achieves similar learning compared with trained $\mathrm{CNN}$ for hip fracture detection

Successful automatic segmentation of the proximal femur using MR images

$\mathrm{CNN}$ model performance is comparable to an attending physician with 10 -year experience
Regarding etiology, the origins of cam and pincer morphologies are still unrecognized although several efforts recently shed light on this topic [70]. Nevertheless, whether sports activity in childhood may influence this (how much is too much?) and why some patients develop symptoms and others do not (load history, load type, load frequency, genetic background, cartilotype etc) still remain to be established.

Diagnosis Diagnosis of FAI syndrome still remains imprecise and needs improvement. Prognosis and long-term natural history remain elusive as considerably better information 
Table 6 Sample questions related to FAI main areas of research for the next decade

\begin{tabular}{|c|c|}
\hline Areas of research & Research questions \\
\hline Etiology & $\begin{array}{l}\text { Which activities predispose to FAI morphology? } \\
\text { What matters the most? Type, frequency or intensity of sports for the development of cam morphology? } \\
\text { Does a balanced activity program prevent the development of cam morphology in an adolescent? } \\
\text { Cause or consequence for pelvis muscle dysfunction and gait patterns in FAIS? } \\
\text { Do other preventive measures and/or rehabilitation prevent FAI morphology and/or pain? } \\
\text { What is the prevalence and incidence of FAI morphology and FAIS? } \\
\text { What other structural factors do predispose to FAIS (besides cam and pincer)? } \\
\text { What are the sources of FAI-related pain? }\end{array}$ \\
\hline Diagnosis & $\begin{array}{l}\text { What is the specific definition of FAI syndrome? } \\
\text { How do we define cam morphology? And the diagnostic criteria for cam associated FAI? } \\
\text { How do we define pincer morphology? And the diagnostic criteria for pincer FAI? } \\
\text { What imaging parameters should be used to define FAI-related morphology? } \\
\text { What thresholds should be used for quantitative parameters in hip imaging? } \\
\text { What is the algorithmic approach for using imaging in FAI? } \\
\text { What is the role for advanced imaging in FAI assessment? }\end{array}$ \\
\hline Prognosis and natural history & $\begin{array}{l}\text { In those with FAI morphology, can we predict who will become symptomatic? } \\
\text { What is the natural history of FAI morphology? } \\
\text { Which factors affect surgical outcomes (e.g. demography, clinical features, imaging parameters)? }\end{array}$ \\
\hline Therapeutic interventions & $\begin{array}{l}\text { What is the outcome of FAI conservative treatment? } \\
\text { FAI surgery compared effectiveness to sham surgery? } \\
\text { Surgery or conservative management effectiveness for improving short- and long-term outcomes? } \\
\text { Which patients respond best to conservative management? And to FAI surgery? } \\
\text { What is the most effective conservative management program? And FAI surgery protocol? } \\
\text { and the optimal post operative rehabilitation program? } \\
\text { What are the best PROMs to use following FAI-treatment? } \\
\text { What is the optimal method to treat labral pathology? And chondral pathology? And capsular approach? } \\
\text { What are the limits of labral and chondral damage that can be treated with hip preserving surgery? } \\
\text { Does operating on asymptomatic hips lead to long-term benefits in terms of reducing FAIS or OA? } \\
\text { What are the return to sport criteria following FAI surgery? }\end{array}$ \\
\hline Future & $\begin{array}{l}\text { Can we use AI to segment, detect and classify FAI patients? } \\
\text { Can we use AI to predict the outcomes of different combinations of demographics, clinical } \\
\text { features and morphologies? } \\
\text { Can we use biobanks, DL and AI to predict prognosis and tailor treatment? }\end{array}$ \\
\hline
\end{tabular}

deriving from long-term prospective studies are missing. Treatment options need to be objectively compared with effectiveness, safety, and cost. The benefits and harms of different interventions and strategies to prevent, diagnose, treat, and monitor FAI syndrome must be the primary concern of future research.

\section{Conclusions}

Practitioners should be aware that imaging assists clinical evaluation and decision making among validated treatment options (Fig. 2). The presence of clinical symptoms and signs suggestive of FAI syndrome may prompt the physician to order conventional radiographs to exclude structural abnormalities. If cam and/or pincer morphology is radiographically evident or exclusion of other mimicking conditions is imperative, a dedicated MRI examination may be performed. In the current clinical state-of-theart setting, a validated imaging assessment for FAI focuses on MRI or MRA evaluation of osseous and soft tissue components of the hip joint. Other advanced imaging techniques may play an important role in the immediate future for detection of early-onset OA, surgical planning, and post-operative follow-up, but their precise impact on clinical decision making, tailored treatment, and PROMs still remains uncertain.

Looking ahead, imaging, AI, and HPS will continue to evolve, with new problems and even greater challenges. The increasing number of analytic parameters describing the hip joint, as well as new sophisticated MRI and imaging analysis, has carried practitioners beyond the point of simplistic classifications. We strive for more reliable treatment guidelines beyond differentiation into pure instability or impingement. It is paramount to refine the diagnostic algorithm to adequately define treatment indications and prognosis. The largely unknown natural FAI syndrome course continues to be a problem as far as diagnosis, treatment, and prognosis are concerned. Nevertheless, the boundaries of morphological, functional, and AI-aided assessment are gradually being pushed to 
new levels and the role of musculoskeletal imaging is rapidly evolving to exciting fields.

\section{Compliance with Ethical Standards}

Conflict of Interest Vasco V. Mascarenhas, António Caetano, Pedro Dantas, and Paulo Rego have no conflict of interest.

Human and Animal Rights and Informed Consent This article does not contain any studies with human or animal subjects performed by any of the authors.

\section{References}

Papers of particular interest, published recently, have been highlighted as:

- Of importance

•. Of major importance

1.• Griffin DR, Dickenson EJ, O'Donnell J, et al. The Warwick Agreement on femoroacetabular impingement syndrome (FAI syndrome): an international consensus statement. Br J Sports Med. 2016;50:1169-76. Consensus statement highlighing the fundamental concepts on FAI and FAIS.

2. Nepple JJ, Prather H, Trousdale RT, Clohisy JC, Beaulé PE, GlynJones S, et al. Clinical diagnosis of femoroacetabular impingement. J Am Acad Orthop Surg. 2013;21(Suppl 1):S16-9. Pioneer work on defining the clinical FAI syndrome.

3. Ganz R, Parvizi J, Beck M, Leunig M, Nötzli H, Siebenrock KA. Femoroacetabular impingement: a cause for osteoarthritis of the hip. Clin Orthop Relat Res. 2003;(417):112-120. https://doi.org/ 10.1097/01.blo.0000096804.78689.c2. Pioneer work on defining the FAI mechanism and its implications.

4. Mascarenhas VV, Rego PA, Dantas P, Caetano AP, Jans L, Sutter $\mathrm{R}$, et al. Can we discriminate symptomatic hip patients from asymptomatic volunteers based on anatomic predictors? A 3-dimensional magnetic resonance study on cam, pincer, and Spinopelvic parameters. Am J Sports Med. 2018;46:3097-110.

5. Agricola R, Heijboer MP, Bierma-Zeinstra SMA, Verhaar JAN, Weinans H, Waarsing JH. Cam impingement causes osteoarthritis of the hip: a nationwide prospective cohort study (CHECK). Ann Rheum Dis. 2013;72:918-23.

6.• Mascarenhas VV, Castro MO, Rego PA, et al. The Lisbon Agreement on Femoroacetabular Impingement Imaging-part 1: overview [published online ahead of print, $2020 \mathrm{Jul} 17$ ] [published correction appears in Eur Radiol 2020 Jul 17]. Eur Radiol 2020. https://doi.org/10.1007/ s00330-020-06822-9. Consensus agreement defining the fundamental concepts on FAI and FAIS.

7.• Mascarenhas VV, Ayeni OR, Egund N, Jurik AG, Caetano A, Castro M, et al. Im aging methodology for hip preservation: techniques, parameters, and thresholds. Semin Musculoskelet Radiol. 2019;23:197-226. Comprehensive review article on the different techniques and parameters used in hip and FAI imaging.

8. Mascarenhas VV, Caetano A. Imaging the young adult hip in the future. Ann Joint. 2018;3:47.

9. Schmaranzer F, Klauser A, Kogler M, Henninger B, Forstner T, Reichkendler M, et al. Diagnostic performance of direct traction MR arthrography of the hip: detection of chondral and labral lesions with arthroscopic comparison. Eur Radiol. 2014;25:1721-30. https://doi.org/10.1007/s00330-014-3534-x.
10. Hemke R, Mascarenhas V, Maas M. Novel imaging techniques in rheumatic diseases. Semin Musculoskelet Radiol. 2018;22:237-44.

11. Bittersohl B, Hosalkar HS, Hesper T, Tiderius CJ, Zilkens C, Krauspe R. Advanced imaging in femoroacetabular impingement: current state and future prospects. Front Surg. 2015;2:608.

12. Rossi MJ, Sheean AJ, Cote MP, Brand JC, Lubowitz JH. The patient-reported outcomes measurement information system (PROMIS): can we finally compare apples to oranges? Arthroscopy. 2020;36:1215-7.

13. Mascarenhas VV, Rego PA, Dantas P, Morais F, McWilliams J, Collado D, et al. Imaging prevalence of femoroacetabular impingement in symptomatic patients, athletes, and asymptomatic individuals: a systematic review. Eur J Radiol. 2016;85:73-95.

14. Lopes DS, Pires SM, Mascarenhas VV, Silva MT, Jorge JA. On a "Columbus' Egg": Modeling the shape of asymptomatic, dysplastic and impinged hip joints. Med Eng Phys. 2018;59:50-55. https:// doi.org/10.1016/j.medengphy.2018.07.001.

15. Rhee C, Le Francois T, Byrd JWT, Glazebrook M, Wong I. Radiographic diagnosis of pincer-type Femoroacetabular impingement: a systematic review. Orthop J Sports Med. 2017;5: 232596711770830

16. Saito M, Tsukada S, Yoshida K, Okada Y, Tasaki A. Correlation of alpha angle between various radiographic projections and radial magnetic resonance imaging for cam deformity in femoral headneck junction. Knee Surg Sports Traumatol Arthrosc. 2017;25(1): 77-83. https://doi.org/10.1007/s00167-016-4046-9.

17. Eijer H, Leunig M, Mahomed N, Ganz R. Cross-table lateral radiographs for screening of anterior femoral head-neck offset in patients with femoro-acetabular impingement. Hip Int. 2001;11:37-41.

18. Mascarenhas VV, Rego PA, Dantas P, Castro M, Jans L, Marques RM, et al. Hip shape is symmetric, non-dependent on limb dominance and gender-specific: implications for femoroacetabular impingement. A 3D CT analysis in asymptomatic subjects. Eur Radiol. 2018;28:1609-24.

19. Mascarenhas VV, Rego P, Dantas P, Gaspar A, Soldado F, Consciência JG. Cam deformity and the omega angle, a novel quantitative measurement of femoral head-neck morphology: a 3D CT gender analysis in asymptomatic subjects. Eur Radiol. 2017;27: 2011-23.

20. Zhang L, Wells JE, Dessouky R, et al. 3D CT segmentation of CAM type femoroacetabular impingement-reliability and relationship of CAM lesion with anthropomorphic features. Br J Radiol. 2018;91(1092):20180371. https://doi.org/10.1259/bjr.20180371.

21. Dessouky R, Chhabra A, Zhang L, Gleason A, Chopra R, Chatzinoff $\mathrm{Y}$, et al. Cam-type femoroacetabular impingement-correlations between alpha angle versus volumetric measurements and surgical findings. Eur Radiol. 2019;29:3431-40.

22. Samim M, Eftekhary N, Vigdorchik JM, Elbuluk A, Davidovitch $\mathrm{R}$, Youm T, et al. 3D-MRI versus 3D-CT in the evaluation of osseous anatomy in femoroacetabular impingement using Dixon 3D FLASH sequence. Skelet Radiol. 2019;48:429-36.

23. Yan K, Xi Y, Sasiponganan C, Zerr J, Wells JE, Chhabra A. Does 3DMR provide equivalent information as 3DCT for the pre-operative evaluation of adult hip pain conditions of femoroacetabular impingement and hip dysplasia? Br J Radiol. 2018;87:20180474.

24. Lerch TD, Degonda C, Schmaranzer F, Todorski I, CullmannBastian J, Zheng G, et al. Patient-specific 3-D magnetic resonance imaging-based dynamic simulation of hip impingement and range of motion can replace 3-D computed tomography-based simulation for patients with femoroacetabular impingement: implications for planning open hip preservation surgery and hip arthroscopy. Am J Sports Med. 2019;47:2966-77.

25. Hanke MS, Steppacher SD, Anwander H, Werlen S, Siebenrock KA, Tannast M. What MRI findings predict failure 10 years after surgery for femoroacetabular impingement? [published correction appears in Clin Orthop Relat Res. 2017 Apr;475(4):1278]. Clin 
Orthop Relat Res. 2017;475(4):1192-1207. https://doi.org/10. 1007/s11999-016-5040-8.

26. Ng VY, Arora N, Best TM, Pan X, Ellis TJ. Efficacy of surgery for femoroacetabular impingement: a systematic review. Am J Sports Med. 2010;38:2337-45.

27. Wells J, Millis M, Kim YJ, Bulat E, Miller P, Matheney T. Survivorship of the bernese periacetabular osteotomy: What factors are associated with long-term failure?. Clin Orthop Relat Res. 2017;475(2):396-405. https://doi.org/10.1007/s11999-016-4887-z.

28. Abrams GD. Editorial commentary: not repairing the hip capsule after arthroscopy-what were we thinking? Arthroscopy. 2018;34: 319-20.

29. Bsat S, Frei H, Beaulé PE. The acetabular labrum: a review of its function. Bone Joint J. 2016;98-B:730-5.

30. Atzmon R, Sharfman ZT, Haviv B, Frankl M, Rotem G, Amar E, et al. Does capsular closure influence patient-reported outcomes in hip arthroscopy for femoroacetabular impingement and labral tear? J Hip Preserv Surg. 2019;6:199-206.

31. Harris JD. Hip labral repair: options and outcomes. Curr Rev Musculoskelet Med. 2016;9(4):361-367. https://doi.org/10.1007/ s12178-016-9360-9.

32. Saied AM, Redant C, El-Batouty M, El-Lakkany MR, El-Adl WA, Anthonissen J, et al. Accuracy of magnetic resonance studies in the detection of chondral and labral lesions in femoroacetabular impingement: systematic review and meta-analysis. BMC Musculoskelet Disord. 2017;18:83.

33. Sutter R, Zubler V, Hoffmann A, Mamisch-Saupe N, Dora C, Kalberer F, et al. Hip MRI: how useful is Intraarticular contrast material for evaluating surgically proven lesions of the labrum and articular cartilage? AJR Am J Roentgenol. 2014;202:160-9.

34. Smith TO, Drew B, Toms AP, Jerosch-Herold C, Chojnowski AJ. Diagnostic accuracy of magnetic resonance imaging and magnetic resonance arthrography for triangular fibrocartilaginous complex injury. J Bone Joint Surg. 2012;94:824-32.

35. Chopra A, Grainger AJ, Dube B, Evans R, Hodgson R, Conroy J, et al. Comparative reliability and diagnostic performance of conventional $3 \mathrm{~T}$ magnetic resonance imaging and $1.5 \mathrm{~T}$ magnetic resonance arthrography for the evaluation of internal derangement of the hip. Eur Radiol. 2018;28:963-71.

36. Crespo-Rodríguez AM, De Lucas-Villarrubia JC, PastranaLedesma M, Hualde-Juvera A, Méndez-Alonso S, Padron M. The diagnostic performance of non-contrast 3-Tesla magnetic resonance imaging (3-T MRI) versus 1.5-Tesla magnetic resonance arthrography (1.5-T MRA) in femoro-acetabular impingement. Eur J Radiol. 2017;88:109-16.

37. Schmaranzer F, Todorski IAS, Lerch TD, Schwab J, CullmannBastian J, Tannast M. Intra-articular lesions: imaging and surgical correlation. Semin Musculoskelet Radiol. 2017;21:487-506.

38. Schumann S, Liu L, Tannast M, Bergmann M, Nolte L-P, Zheng G. An integrated system for 3D hip joint reconstruction from 2D Xrays: a preliminary validation study. Ann Biomed Eng. 2013;41: 2077-87.

39. Audenaert EA, Baelde N, Huysse W, Vigneron L, Pattyn C. Development of a three-dimensional detection method of cam deformities in femoroacetabular impingement. Skelet Radiol. 2011;40:921-7.

40. Chandra SS, Xia Y, Engstrom C, Crozier S, Schwarz R, Fripp J. Focused shape models for hip joint segmentation in 3D magnetic resonance images. Med Image Anal. 2014;18:567-78.

41. Zeng G, Zheng G. Deep volumetric shape learning for semantic segmentation of the hip joint. Springer Nature Switzerland AG 2019 T. Vrtovec et al. (Eds.): MSKI 2018, LNCS 11404, pp. 3548, 2019. https://doi.org/10.1007/978-3-030-11166-3 4

42. Bien N, Rajpurkar P, Ball RL, Irvin J, Park A, Jones E, et al. Deeplearning-assisted diagnosis for knee magnetic resonance imaging: development and retrospective validation of MRNet. PLoS Med. 2018;15:e1002699.

43. Hellwig FL, Tong J, Hussell JG. Hip joint degeneration due to cam impingement: a finite element analysis. Comput Methods Biomech Biomed Engin. 2016;19:41-8.

44. Albers CE, Hanke MS, Ecker TM, Haefeli PC, Siebenrock KA, Steppacher SD, et al. Computer assisted diagnosis and treatment planning of femoroacetabular impingement (FAI). In: Lecture notes in computational vision and biomechanics. Cham: Springer International Publishing; 2015. p. 173-96.

45. Atkins PR, Aoki SK, Whitaker RT, Weiss JA, Peters CL, Anderson AE. Does removal of subchondral cortical bone provide sufficient resection depth for treatment of cam femoroacetabular impingement?. Clin Orthop Relat Res. 2017;475(8):1977-1986. https:// doi.org/10.1007/s11999-017-5326-5.

46. Breighner RE, Bogner EA, Lee SC, Koff MF, Potter HG. Evaluation of osseous morphology of the hip using zero Echo time magnetic resonance imaging. Am J Sports Med. 2019;47:3460-8.

47. Florkow MC, Zijlstra F, Willemsen K, et al. Deep learning-based MR-to-CT synthesis: the influence of varying gradient echo-based MR images as input channels. Magn Reson Med. 2019;83:1429 41.

48. Samaan MA, Zhang AL, Gallo MC, Schwaiger BJ, Link TM, Souza RB, et al. Quantitative magnetic resonance arthrography in patients with femoroacetabular impingement. J Magn Reson Imaging. 2016;44:1539-45.

49. Schmaranzer F, Helfenstein R, Zeng G, Lerch TD, Novais EN, Wylie JD, et al. Automatic MRI-based three-dimensional models of hip cartilage provide improved morphologic and biochemical analysis. Clin Orthop Relat Res. 2019;477:1036-52.

50. Röling MA, Visser MI, Oei EHG, Pilot P, Kleinrensink G-J, Bloem RM. A quantitative non-invasive assessment of femoroacetabular impingement with CT-based dynamic simulation-cadaveric validation study. BMC Musculoskelet Disord. 2015;16:50.

51. Lerch TD, Siegfried M, Schmaranzer F, Leibold CS, Zurmühle CA, Hanke MS, et al. Location of intra- and extra-articular hip impingement is different in patients with pincer-type and mixed-type femoroacetabular impingement due to acetabular retroversion or protrusio acetabuli on 3D CT-based impingement simulation. Am J Sports Med. 2020;48:661-72.

52. Tannast M, Kubiak-Langer M, Langlotz F, Puls M, Murphy SB, Siebenrock KA. Noninvasive three-dimensional assessment of femoroacetabular impingement. J Orthop Res. 2006;25:122-31.

53. Van Houcke J, Khanduja V, Nakano N, Krekel P, Pattyn C, Audenaert E. Accuracy of navigated cam resection in femoroacetabular impingement: a randomised controlled trial. Int J Med Rob Comput Assist Surg. 2017;13:e1839.

54. Buchan LL, Zhang H, Konan S, Heaslip I, RatzlaffCR, Wilson DR. Open-MRI measures of cam intrusion for hips in an anterior impingement position relate to acetabular contact force. J Orthop Res. 2015;34:205-16.

55. Wassilew GI, Janz V, Heller MO, Tohtz S, Rogalla P, Hein P, et al. Real time visualization of femoroacetabular impingement and subluxation using 320-slice computed tomography. J Orthop Res. 2012;31:275-81.

56. Fernquest S, Arnold C, Palmer A, Broomfield J, Denton J, Taylor A, et al. Osseous impingement occurs early in flexion in cam-type femoroacetabular impingement: a 4D CT model. Bone Joint J. 2017;99-B:41-8.

57. Burke CJ, Walter WR, Gyftopoulos S, Pham H, Baron S, GonzalezLomas G, et al. Real-time assessment of femoroacetabular motion using radial gradient echo magnetic resonance arthrography at 3 tesla in routine clinical practice: a Pilot study. Arthroscopy. 2019;35:2366-74.

58. Wong TT, Lynch TS, Popkin CA, Kazam JK. Preoperative use of a 3D printed model for femoroacetabular impingement surgery and 
its effect on planned osteoplasty. AJR Am J Roentgenol. 2018;211: W116-21.

59. Flecher X, Migaud H. From radiographs to 3D printing: how can new surgical planning technologies contribute to hip surgery? Orthopa Traumatol Surg Res : OTSR. 2017;103:323-4.

60. Ma D, Gulani V, Seiberlich N, Liu K, Sunshine JL, Duerk JL, et al. Magnetic resonance fingerprinting. Nature. 2013;495:187-92.

61. Kooijman MN, Kruithof CJ, van Duijn CM, Duijts L, Franco OH, van IJzendoorn $\mathrm{MH}$, et al. The generation $\mathrm{R}$ study: design and cohort update 2017. Eur J Epidemiol. 2016;31:1243-64.

62. Anoushiravani AA, Patton J, Sayeed Z, El-Othmani MM, Saleh KJ. Big data, big research: implementing population health-based research models and integrating care to reduce cost and improve outcomes. Orthop Clin North Am. 2016;47:717-24.

63. Aphinyanaphongs Y. Big data analyses in health and opportunities for research in radiology. Semin Musculoskelet Radiol. 2017;21: 032-6.

64. Tachmazidou I, Hatzikotoulas K, Southam L, et al. Identification of new therapeutic targets for osteoarthritis through genome-wide analyses of UK Biobank data. Nat Genet. 2019;51:230-6.
65. Coppola L, Cianflone A, Grimaldi AM, et al. Biobanking in health care: evolution and future directions. J Transl Med. 2019;17(1):172. https://doi.org/10.1186/s12967-019-1922-3.

66. Recht M, Bryan RN. Artificial intelligence: threat or boon to radiologists? J Am Coll Radiol. 2017;14:1476-80.

67. Syed AB, Zoga AC. Artificial intelligence in radiology: current technology and future directions. Semin Musculoskelet Radiol. 2018;22:540-5.

68. Xue Y, Zhang R, Deng Y, Chen K, Jiang T. A preliminary examination of the diagnostic value of deep learning in hip osteoarthritis. PLoS One. 2017;12:e0178992.

69. von CE S, Sohn JH, Liu F, et al. Development and validation of a multitask deep learning model for severity grading of hip osteoarthritis features on radiographs. Radiology. 2020;295:136-45.

70. van Klij P, Heijboer MP, Ginai AZ, Verhaar JAN, Waarsing JH, Agricola R. Cam morphology in young male football players mostly develops before proximal femoral growth plate closure: a prospective study with 5-yearfollow-up. Br J Sports Med. 2019;53: $532-8$.

Publisher's Note Springer Nature remains neutral with regard to jurisdictional claims in published maps and institutional affiliations. 